\title{
Surgical versus non-surgical treatment for acute anterior shoulder dislocation (Review)
}

\author{
Handoll HHG, Al-Maiyah MA
}

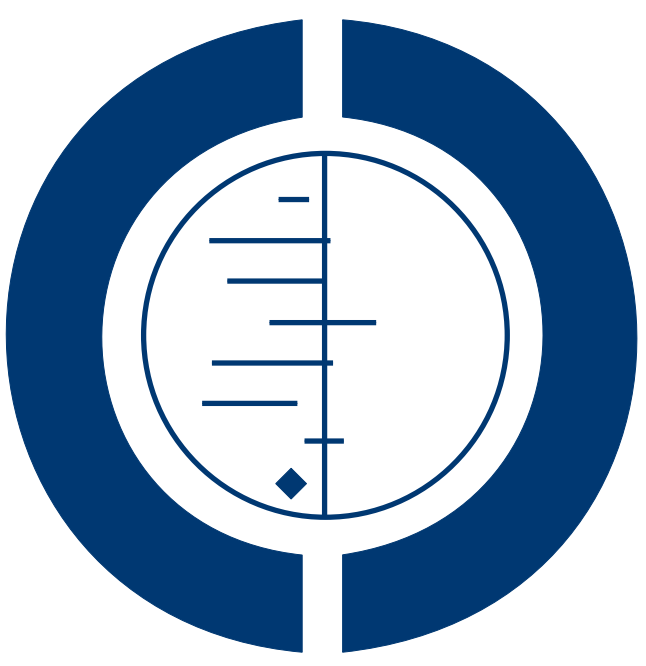

\section{THE COCHRANE COLLABORATION $^{\circledR}$}

This is a reprint of a Cochrane review, prepared and maintained by The Cochrane Collaboration and published in The Cochrane Library 2010, Issue 1

http://www.thecochranelibrary.com

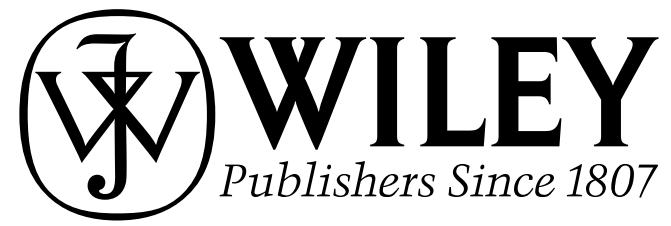

Surgical versus non-surgical treatment for acute anterior shoulder dislocation (Review)

Copyright (C) 2010 The Cochrane Collaboration. Published by John Wiley \& Sons, Ltd. 
TABLE OF CONTENTS

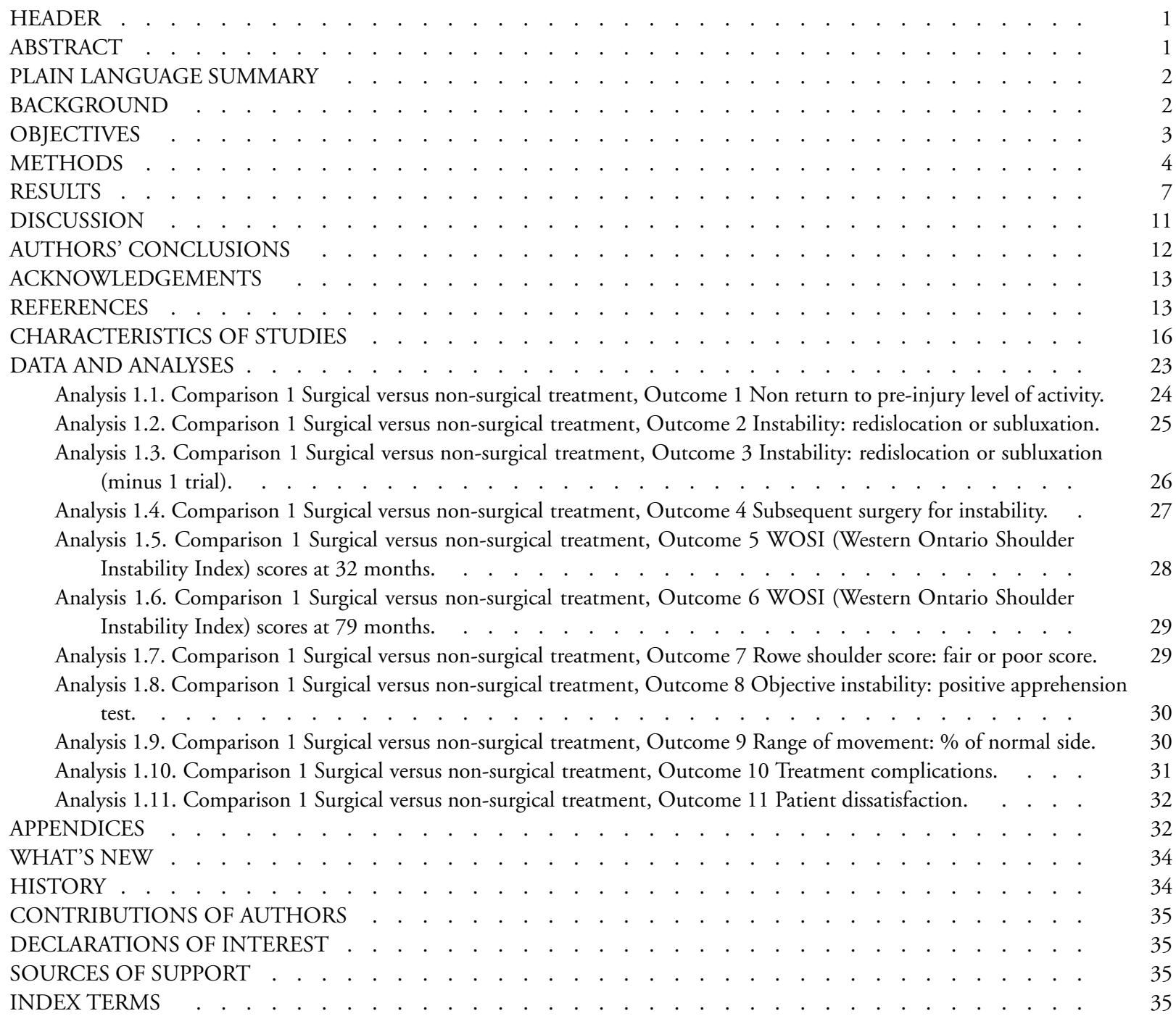

Surgical versus non-surgical treatment for acute anterior shoulder dislocation (Review)

Copyright (C) 2010 The Cochrane Collaboration. Published by John Wiley \& Sons, Ltd. 


\title{
[Intervention Review]
}

\section{Surgical versus non-surgical treatment for acute anterior shoulder dislocation}

\author{
Helen HG Handoll ${ }^{2}$, Mohammed A Al-Maiyah ${ }^{1}$
}

${ }^{1}$ c/o Mr Rangan's Secretary, Trauma \& Orthopaedic Department, Middlesbrough, UK. ${ }^{2}$ Centre for Rehabilitation Sciences (CRS), Research Institute for Health Sciences and Social Care, University of Teesside, Middlesborough, UK

Contact address: Mohammed A Al-Maiyah, c/o Mr Rangan's Secretary, Trauma \& Orthopaedic Department, The James Cook University Hospital, Marton Road, Middlesbrough, Cleveland, TS4 3BW, UK. mamaiyah@yahoo.co.uk. mamaiyah@doctors.net.uk.

Editorial group: Cochrane Bone, Joint and Muscle Trauma Group.

Publication status and date: New search for studies and content updated (no change to conclusions), published in Issue 1, 2010.

Review content assessed as up-to-date: 13 August 2009.

Citation: Handoll HHG, Al-Maiyah MA. Surgical versus non-surgical treatment for acute anterior shoulder dislocation. Cochrane Database of Systematic Reviews 2004, Issue 1. Art. No.: CD004325. DOI: 10.1002/14651858.CD004325.pub2.

Copyright (C) 2010 The Cochrane Collaboration. Published by John Wiley \& Sons, Ltd.

\section{A B S T R A C T}

\section{Background}

Acute anterior dislocation is the commonest type of shoulder dislocation. Subsequently, the shoulder is less stable and more susceptible to redislocation, especially in active young adults.

\section{Objectives}

To compare surgical versus non-surgical treatment for acute anterior dislocation of the shoulder.

\section{Search strategy}

We searched the Cochrane Bone, Joint and Muscle Trauma Group Specialised Register (14 August 2009), The Cochrane Library (2009, Issue 3), MEDLINE (1950 to August 2009), EMBASE (1980 to August 2009), trial registration databases, conference proceedings and reference lists of articles.

\section{Selection criteria}

Randomised or quasi-randomised controlled trials comparing surgical with conservative interventions.

\section{Data collection and analysis}

Both authors independently selected trials, assessed methodological quality and extracted data. Where appropriate, results were pooled.

\section{Main results}

The four included studies involved 163 participants, mainly active young adult males. All had had a primary (first time) traumatic anterior shoulder dislocation. Methodological quality was variable.

All participants of one trial returned to active military duty. Two trials respectively reported similar numbers with reduced sports participation or non return to previous activities. The other, an inadequately reported, trial found significantly fewer people in the surgical group failed to attain previous levels of sports activity.

Pooled results from all four trials showed that subsequent instability, either redislocation or subluxation, was statistically significantly less frequent in the surgical group (risk ratio $0.25,95 \%$ confidence interval 0.14 to 0.44 ). This result remained statistically significant 
(risk ratio $0.32,95 \%$ confidence interval 0.17 to 0.59 ) for the three trials reported in full. Half (17/33) of the conservatively treated patients with shoulder instability in these three trials opted for subsequent surgery.

Different, mainly patient rated, functional assessment measures for the shoulder were recorded in these trials. The results were more favourable, usually statistically significantly so, in those treated surgically.

The only complication reported was a septic joint in a surgically treated patient. There was no information on shoulder pain, longterm complications or resource use.

\section{Authors' conclusions}

Limited evidence supports primary surgery for young adults, usually male, engaged in highly demanding physical activities who have sustained their first acute traumatic shoulder dislocation. There is no evidence available to determine which treatment is better for other patient groups.

Sufficiently powered, good quality, well reported randomised trials are required that compare surgical treatment with conservative treatment for these injuries, including in people at lower risk of recurrence. Long-term surveillance of outcome, looking at shoulder disorders including osteoarthritis is also required.

\section{PLAIN LANGUAGE SUMMARY}

\section{Surgical versus non-surgical treatment for acute anterior shoulder dislocation}

Acute anterior shoulder dislocation occurs where the top end of the humerus (the upper arm bone) is pushed out of the joint socket in a forward direction, usually as a result of an accident such as a fall. Initial treatment requires putting the joint back together. Subsequent treatment is either non-surgical, involving placing the arm in a sling followed by exercises, or surgical, involving repair of damaged structures or cleaning up the joint space.

This review included four trials that involved 163 participants who were mainly active young adult males. All had had a primary (first time) anterior shoulder dislocation as a result of injury. Methodological quality of the trials was variable. Three trials found similar numbers returning to previous activities such as active military duties and sports. The other trial found significantly fewer people in the surgical group failing to attain previous levels of sports activity.

Pooled results from the three trials that were reported in full (124 participants) showed that subsequent instability, either redislocation or subluxation (partial dislocation), was significantly less frequent in the surgical group. Half (17/33) of the conservatively treated patients with shoulder instability in these three trials opted for subsequent surgery. Function, measured in different ways in the four trials, was usually better in those treated surgically. The only complication of treatment reported was an infected joint in a surgically treated patient.

This review found that highly active young people were less likely to have an unstable shoulder when treated surgically after an acute anterior shoulder dislocation.

\section{B A C K G R O U N D}

\section{Description of the condition}

Of the large joints, the shoulder is the one that most commonly dislocates. The shoulder joint has the greatest range of motion of all the joints in the human body. It is this extreme range of motion that also renders the shoulder the most unstable joint in the body (Kazar 1969). Gleno-humeral (shoulder joint) instabil- ity encompasses a spectrum of disorders (O'Brien 1987). These vary from minor subluxation (partial dislocation) to full dislocation where the articular surfaces of the gleno-humeral joint are no longer in contact. Instability may be either anterior (forwards), posterior (backwards) or multidirectional. Symptomatic episodes may be acute, recurrent or chronic; they most commonly follow a traumatic event but may occur spontaneously, perhaps due to some congenital joint laxity.

Anterior traumatic dislocation, where the proximal end of the 
humerus (upper arm bone) is pushed out of the joint socket in a forward direction, constitutes $96 \%$ of all shoulder dislocations ( Goss 1988). Once a dislocation has occurred, the shoulder is less stable and more susceptible to redislocation. Recurrence has been reported to be as high as 92\% (Rowe 1956).

A population study conducted in Sweden (Hovelius 1982), which examined the prevalence of a history of shoulder dislocation in a random sample of 2092 people in the 18 to 70 years age group, found that $35(1.7 \%)$ reported such a history. There was a male to female ratio of three to one; this ratio varied with age. In the 21 to 30 years age group, Hovelius recorded a nine to one male predominance, whereas there was a three to one female predominance in the 50 to 70 age group. A study based in the USA reported an overall adjusted incidence of initial traumatic shoulder dislocation of 8.2/100,000 person years (Simonet 1984). The incidence of all traumatic shoulder dislocations, initial and recurrent, was estimated to be at least 11.2/100,000 person years. Simonet 1984 further estimated prevalence expressed in terms of a cumulative incidence rate of $0.7 \%$ for men and $0.3 \%$ for women up to the age of 70 years. Although shoulder dislocation is generally considered an injury of young adults, Rowe found that there were as many initial dislocations after age 45 as before age 45 (Rowe 1956). However, recurrent dislocation tends to be more common in younger adults. For instance, a 10 year follow-up evaluation found that $66 \%$ of those aged between 12 and 22 years at the time of their first dislocation had one or more recurrences; whereas $24 \%$ had a recurrence in those aged between 30 and 40 years (Hovelius 1996).

Traumatic shoulder dislocation, which involves a complete separation of the joint surfaces, usually results in damage to the soft tissue surrounding the shoulder joint. While the nature and extent of damage varies, there are some frequently found injury patterns such as the classical Bankart lesion (the separation of anterior capsule and labrum from the glenoid rim) (Bankart 1938), the Hill Sachs lesion (compression fracture of the humeral head) (Hill 1940), and dysfunction of the subscapularis muscle (De Palma 1983).

There is no single pathologic lesion that is common to all recurrent dislocations (Morrey 1981). Fleega devised an anatomical classification to describe the pathology of recurrent dislocation. This includes the capsule and ligaments, the glenoid, the humeral head and the muscles or muscle tendons; defects in each one of these or in combination can cause recurrent dislocation (Fleega 1991).

\section{Description of the intervention}

Shoulder dislocation and its treatment have been recorded since ancient times. Hippocrates, in his writings, revealed firm convictions regarding the different types of recurrent dislocation, the seriousness of the lesions and methods of treatment. His treatments included the cauterisation of the deep tissues in front of the shoulder for chronic instability (De Palma 1983).
Present day treatment, which aims at restoration of a fully functioning, pain-free and stable shoulder, comprises either conservative (non-surgical) or surgical management. Both are generally preceded by reduction of the acute dislocation. Subsequent conservative management usually comprises a period of rest, generally involving immobilisation of the arm in a sling, for three to six weeks followed by a supervised physiotherapy programme ( O'Brien 1987). Operative management, which may involve open or arthroscopic surgery, is usually followed by a supervised physiotherapy programme. Nowadays, surgical interventions generally aim to restore normal anatomy, such as the Bankart procedure involving repair of the Bankart lesion. However, in some surgical methods, such as the Putti-Platt procedure, tendon or muscles are shortened/transferred in an attempt to stabilise and strengthen the shoulder joint.

In essence, there is a spectrum of treatment ranging from initial immobilisation followed by rehabilitation to immediate surgical repair in selected cases (Hawkins 1991). The choice of treatment will be influenced by patient age and previous history of dislocation, occupation, level of activity, general health, ligamentous laxity and the reliability to carry out a prescribed therapeutic regime. Generally, surgical intervention has been reserved for chronic recurrence or instability.

\section{Why it is important to do this review}

Given the high rate of recurrence, especially in young physically active adults, a key area of controversy is the management of traumatic first-time anterior dislocation and whether surgical treatment of primary dislocation is warranted. Thus, the main focus of this review is whether a patient within the late adolescent to middle-aged adult category presenting with first-time dislocation should be offered surgical treatment. We also plan to address this question for the whole population, including children and older adults. However, so far, as we anticipated, we have located no randomised controlled trials specific to children, in whom anterior shoulder dislocation is rare, or for older adults, whose risk of recurrence is less.

\section{O B J E C T I V E S}

The objective of this review was to assess the effects of surgical versus non-surgical treatment for treating acute anterior shoulder dislocation.

The main focus was on physically active individuals with primary dislocation who fall in the late adolescent to young adult category (nominally defined as between 16 and 30 years). This was mainly because there is some evidence that these individuals have highest risk of recurrent dislocation. 
If the data were available, we planned to compare outcomes of different groups, specifically:

- people with primary dislocations versus those with recurrent dislocations;

- physically active young to middle-aged adults versus those not falling into this category.

\section{METHODS}

\section{Criteria for considering studies for this review}

\section{Types of studies}

Any randomised or quasi-randomised (for example, allocation by date of birth or alternation) controlled trials which compare surgical and non-surgical interventions for the treatment of acute anterior shoulder dislocation.

\section{Types of participants}

People with acute anterior shoulder dislocation confirmed by physical examination and radiography (X-ray) or some other imaging modality such as magnetic resonance imaging (MRI). The potential for misdiagnosis, such as a missed proximal humeral fracture, was considered in trials in which the method of diagnosis is unspecified or based on physical examination alone.

\section{Types of interventions}

Any surgical (open or minimal access) treatment intervention when compared with a non-surgical treatment intervention for acute anterior shoulder dislocation. Surgical intervention included diagnostic arthroscopy and arthroscopic lavage. We excluded trials where diagnostic arthroscopy was a component of the supposed 'non-surgical' intervention.

\section{Types of outcome measures}

\section{Primary outcomes}

1. Recovery defined as return to pre-injury level of activity (sports or work).

2. Re-injury or recurrence (including subsequent surgery).

3. Persistent pain (long-term).

4. Subjective instability.

5. Results from patient functional assessment measures such as Short Form-36 (SF-36), the Disability of the Arm, Shoulder, and
Hand questionnaire (DASH) and other validated shoulder rating scales.

\section{Secondary outcomes}

1. Objective instability (e.g. apprehension test).

2. Stiffness.

3. Range of movement.

4. Muscle strength.

5. Complications (e.g. sensory deficit, infection, osteoarthritis)

6. Satisfaction.

In addition, we sought data on service utilisation or resource use; for instance, length of hospital stay, outpatient attendance and the provision and nature of physiotherapy.

\section{Search methods for identification of studies}

\section{Electronic searches}

We searched the Cochrane Bone, Joint and Muscle Trauma Group Specialised Register (14 August 2009), the Cochrane Central Register of Controlled Trials (The Cochrane Library 2009, Issue 3), MEDLINE (1950 to August 2009), MEDLINE in progress (14 August 2009) and EMBASE (1980 to 2009 Week 32). No language restrictions were applied.

See Appendix 1 for the search strategies for The Cochrane Library, MEDLINE and EMBASE. In MEDLINE the subject-specific strategy (lines 1 to 11 ) was combined with the three stages of the Cochrane trial search strategy (Higgins 2006), and modified for use in EMBASE.

We also searched Current Controlled Trials (accessed 14 September 2009), the WHO International Clinical Trials Registry Platform (accessed 14 September 2009) and the National Research Register (NRR) Archive (to September 2007) for ongoing and recently completed trials.

\section{Searching other resources}

We searched the reference list of articles. We also searched the conference proceedings of the British Elbow and Shoulder Society (2001 to 2009), SICOT/SIROT Second Annual International Conference 2003, the British Orthopaedic Association Annual Congress (2003, 2005, 2006), the 2002 and 2003 meetings of the British Trauma Society, and EFORT (2007). We also handsearched conferences proceedings published in the supplements of the Journal of Bone and Joint Surgery - British Volume (2004, 2005 and 2006) and Injury (2004). 


\section{Data collection and analysis}

\section{Selection of studies}

Both review authors assessed potentially eligible trials for inclusion, any disagreement being resolved through discussion. Titles of journals, names of authors or supporting institutions were not masked at any stage.

\section{Data extraction and management}

Data were extracted independently by both authors using piloted forms. Discrepancies were resolved through discussion. Several attempts were made to contact those trialists whose trials were reported only in conference abstracts for additional details of trial methodology and findings.

\section{Assessment of risk of bias in included studies}

The methodological quality of included studies was assessed independently by both authors using piloted forms. Discrepancies were resolved through discussion. A modification of the Cochrane Bone, Joint and Muscle Trauma Group's former quality assessment tool (see BJMT website for details) was used in the evaluation of the included studies. Table 1 shows the scoring scheme based on 12 aspects of trial methodology. From the third update, we replaced the scores 2, 1, 0 respectively by $\mathrm{Y}$ (yes, criterion satisfied), ? (unclear or criterion partially satisfied), and N (no, criterion not satisfied). Additionally we separately rated the risk of bias from inadequate sequence generation and pre-allocation disclosure of assignment using the risk of bias tool.

Table 1. Methodological quality assessment scheme

\begin{tabular}{l|l|l}
\hline Item & Scores & Notes \\
\hline $\begin{array}{l}\text { A. Was the assigned treatment adequately } \\
\text { concealed prior to allocation? }\end{array}$ & $\begin{array}{l}\mathrm{Y}=\text { method did not allow disclosure of as- } \\
\text { signment. } \\
?=\text { small but possible chance of disclosure } \\
\text { of assignment or unclear. } \\
\mathrm{N}=\text { quasi-randomised or open list/tables. }\end{array}$ \\
\hline $\begin{array}{ll}\text { B. Were the outcomes of participants who } \\
\text { withdrew described and included in the }\end{array}$ & $\begin{array}{l}\mathrm{Y}=\text { withdrawals well described and ac- } \\
\text { counted for in analysis. } \\
\text { analysis (intention-to-treat)? }\end{array}$ & $\begin{array}{l}\text { possible. } \\
\text { polthdrals described and analysis not } \\
\text { N = no mention, inadequate mention, or } \\
\text { obvious differences and no adjustment. }\end{array}$ \\
\hline
\end{tabular}

Surgical versus non-surgical treatment for acute anterior shoulder dislocation (Review) 
C. Were the outcome assessors blinded to $\mathrm{Y}=$ effective action taken to blind assessors. treatment status?

$?=$ small or moderate chance of unblinding of assessors, or some blinding of outcomes attempted.

$\mathrm{N}=$ not mentioned or not possible.

D. Were important baseline characteristics $\mathrm{Y}=$ good comparability of groups. reported and comparable?
? = confounding small, or comparability reported in text without confirmatory data. $\mathrm{N}=$ large potential for confounding, or not discussed.
The principal confounders considered were age, time since injury, primary or repeat dislocation, previous upper-arm injury, presence of other shoulder injuries, hand dominance and type of sporting activity.

E. Were the participants blind to assignment status after allocation?

$\mathrm{Y}=$ effective action taken to blind participants.

$?=$ small or moderate chance of unblinding of participants.

$\mathrm{N}=$ not possible, or not mentioned (unless double-blind), or possible but not done.

F. Were the treatment providers blind to $\mathrm{Y}=$ effective action taken to blind treatment assignment status? providers.

? = small or moderate chance of unblinding of treatment providers.

$\mathrm{N}=$ not possible, or not mentioned (unless double-blind), or possible but not done.

G. Were care programmes, other than the $Y=$ care programmes clearly identical. trial options, identical?
? = clear but trivial differences, or some evidence of comparability.

$\mathrm{N}=$ not mentioned or clear and important differences in care programmes.
Examples of clinically important differences in other interventions considered were: differences in anaesthesia, clinician experience and speciality (fully trained orthopaedic surgeons, others), and subsequent rehabilitation.

H. Were the inclusion and exclusion crite- $\mathrm{Y}=$ clearly defined (including whether priria for entry clearly defined? mary or secondary dislocation).

? = inadequately defined.

$\mathrm{N}=$ not defined.

I. Were the interventions clearly defined? $\quad \mathrm{Y}=$ clearly defined interventions are applied with a standardised protocol.

$?=$ clearly defined interventions are applied but the application protocol is not standardised.

$\mathrm{N}$ = intervention and/or application protocol are poorly or not defined.

J. Were the outcome measures used clearly $\mathrm{Y}=$ clearly defined. defined?

$?=$ inadequately defined. 
Table 1. Methodological quality assessment scheme (Continued)

$\mathrm{N}=$ not defined.

K. Were the outcome measures/diagnostic $\mathrm{Y}=$ optimal. tests used in outcome assessment appropri- $\quad ?=$ adequate. ate? $\quad \mathrm{N}=$ not defined or adequate.

L. Was the surveillance active and of clini- $\mathrm{Y}=$ active surveillance and appropriate ducally appropriate duration? ration (1 year or more). $?=$ active surveillance, but inadequate duration.

$\mathrm{N}=$ surveillance not active or not defined.

\section{Measures of treatment effect}

Where available and appropriate, quantitative data for outcomes (see Types of outcome measures) are presented in the analyses. Risk ratios and 95\% confidence intervals were calculated for dichotomous outcomes, and mean differences and $95 \%$ confidence intervals calculated for continuous outcomes.

\section{Assessment of heterogeneity}

Heterogeneity was assessed by visual inspection of the forest plot (analysis) along with consideration of the $\mathrm{chi}^{2}$ test for heterogeneity and the $\mathrm{I}^{2}$ statistic (Higgins 2003). Heterogeneity was considered statistically significant at $\mathrm{P}<0.1$.

\section{Data synthesis}

Results of comparable groups of trials were pooled using the fixedeffect model and 95\% confidence intervals. Where there is clear or significant heterogeneity, we viewed the results of the randomeffects model but in such cases opted not to pool data where the outcome measures were clearly different.

\section{Subgroup analysis and investigation of heterogeneity}

We planned separate outcome analyses of a) patients with primary dislocations compared with those with recurrent dislocations and b) physically active young to middle-aged adults who constitute the main category of people at risk of this injury and those not falling into this category. Where appropriate, indirect comparisons of fundamentally different treatment interventions, such as open and arthroscopic surgery, were also planned. These, however, were never intended to pre-empt the need for direct comparisons of different types of surgical or non-surgical treatment options which are the basis of separate reviews. If, in a future update, we wish to test whether subgroups are statistically significantly different from one another, we will test the interaction using the technique outlined in Altman 2003.

\section{Sensitivity analysis}

Where appropriate, we planned sensitivity analyses investigating the effects of allocation concealment, assessor blinding, loss to follow-up and publication status.

\section{R E S U L T S}

\section{Description of studies}

See: Characteristics of included studies; Characteristics of excluded studies.

In this third update of our review, we extended the literature search from June 2007 to August 2009. We located one new conference abstract for Kirkley 1999 and the full report of an already excluded trial (White 2003), now renamed Robinson 2008. A short report of a potentially relevant trial published in German (Helms 2008) was found to be a commentary on Robinson 2008.

Out of 11 eligible studies, four are included and the other seven are excluded for reasons given in the Characteristics of excluded studies.

Three included studies (Bottoni 2002; Kirkley 1999; Wintzell 1999) were fully reported in medical journals. The other included trial (Sandow 1996) was reported only in conference abstracts. No further information has been received for Sandow 1996. Most of the trial reports of the included trials were identified from the Specialised Register of the Cochrane Bone, Joint and Muscle Trauma 
Group, the trials having been originally found by handsearching of conference proceedings (2) and MEDLINE (2). All the trials were reported in English.

The publication dates of the full reports of the trials span seven years, from 1996 to 2002. Only Bottoni 2002 gave details of the period of trial recruitment: November 1994 to April 1998. One trial (Sandow 1996) took place in single centres in two countries, Australia and USA. Bottoni 2002 took place in a single centre in the USA. Kirkley 1999 involved two centres in Canada. Initially, recruitment for Wintzell 1999 took place in one centre before being extended to three other centres in Sweden.

The four included studies involved a total of 163 participants, who were mostly young active males. Where data were provided, the percentage of males ranged from $77 \%$ to $100 \%$. The mean age of the trial populations was 22 years in Bottoni 2002 and Kirkley 1999, 24 years in Wintzell 1999, but not provided by Sandow 1996. The youngest recorded patient was 14 years old in Sandow 1996 and the oldest were 30 years in Kirkley 1999 and Wintzell 1999. Though it is likely that the majority of the participants were skeletally mature, only Kirkley 1999 specified this as a criterion for study inclusion. Upper age limits were clearly set by all four trials (Bottoni 2002 and Sandow 1996: 26 years; Kirkley 1999 and Wintzell 1999: 30 years).

All four trials only included patients with primary traumatic anterior shoulder dislocation. The diagnosis was verified by clinical and radiological examination in Kirkley 1999 and Wintzell 1999. Magnetic resonance imaging was used for evaluation af- ter reduction in Bottoni 2002. No details of the diagnosis were provided in Sandow 1996. The various exclusion criteria, such as tuberosity fractures, listed in the trial reports can be viewed in the Characteristics of included studies table. It was not clear whether the exclusion of a bony Bankart lesion or a rotator cuff tear was post randomisation in Sandow 1996; these injuries having been probably diagnosed during surgery.

All four trials compared two treatments, one surgical with one non-surgical. Surgery involved arthroscopic repair in three trials (Bottoni 2002; Kirkley 1999; Sandow 1996) and arthroscopic lavage in Wintzell 1999. Arthroscopic stabilisation was performed using bioabsorbable tacks in Bottoni 2002, K-wires (metal) in Kirkley 1999 and a bio-absorbable implant in Sandow 1996. Nonsurgical and postsurgical treatment comprised sling immobilisation and rehabilitation. Sling use for up to one week was optional in Wintzell 1999. In the other trials, sling immobilisation was three weeks in Kirkley 1999 and four weeks in Bottoni 2002 and Sandow 1996.

Further details of the individual trials are presented in the Characteristics of included studies table.

\section{Risk of bias in included studies}

None of the four trials satisfied the criteria for all of the items of methodological quality (Table 2: items A to $\mathrm{L}$ are described in Table 1).

Table 2. Methodological quality assessment results for individual trials

\begin{tabular}{l|l|l|l|l}
\hline Items / Trials & Bottoni 2002 & Kirkley 1999 & Sandow 1996 & Wintzell 1999 \\
\hline $\begin{array}{l}\text { A. Allocation conceal- } \\
\text { ment }\end{array}$ & $\mathrm{N}$ & $\mathrm{Y}$ & ? & ? \\
\hline $\begin{array}{l}\text { B. Intention-to-treat } \\
\text { analysis }\end{array}$ & ? & ? & $\mathrm{N}$ & $\mathrm{Y}$ \\
\hline $\begin{array}{l}\text { C. Assessor blinding } \\
\text { D. Baseline characteris- }\end{array}$ & $\mathrm{N}$ & $\mathrm{Y}$ & $\mathrm{N}$ & $\mathrm{N}$ \\
\hline $\begin{array}{l}\text { tics comparability } \\
\text { E. Participant blinding }\end{array}$ & $\mathrm{N}$ & $\mathrm{Y}$ & $\mathrm{N}$ & $\mathrm{Y}$ \\
\hline $\begin{array}{l}\text { F. Treatment provider } \\
\text { blinding }\end{array}$ & $\mathrm{N}$ & $\mathrm{N}$ & $\mathrm{N}$ & $\mathrm{N}$ \\
\hline $\begin{array}{l}\text { G. Care programme } \\
\text { comparability }\end{array}$ & $\mathrm{Y}$ & $\mathrm{N}$ & $\mathrm{N}$ & $\mathrm{N}$ \\
\hline
\end{tabular}


Table 2. Methodological quality assessment results for individual trials (Continued)

\begin{tabular}{|c|c|c|c|c|}
\hline $\begin{array}{l}\text { H. Inclusion and exclu- } \\
\text { sion criteria }\end{array}$ & $\mathrm{Y}$ & $\mathrm{Y}$ & $?$ & $\mathrm{Y}$ \\
\hline $\begin{array}{l}\text { I. Clearly defined inter- } \\
\text { ventions? }\end{array}$ & Y & Y & ? & ? \\
\hline $\begin{array}{l}\text { J. Well defined outcome } \\
\text { measures }\end{array}$ & $\mathrm{Y}$ & $\mathrm{Y}$ & $?$ & $\mathrm{Y}$ \\
\hline $\begin{array}{l}\text { K. Clinically useful diag- } \\
\text { nostic tests }\end{array}$ & $\mathrm{Y}$ & Y & $?$ & ? \\
\hline $\begin{array}{l}\text { L. Adequate duration of } \\
\text { follow-up }\end{array}$ & $\mathrm{Y}$ & $\mathrm{Y}$ & $\mathrm{Y}$ & $\mathrm{Y}$ \\
\hline
\end{tabular}

Y: yes

?: partial/unknown

N: no

The assessment of risk of bias associated with allocation for each trial is shown in the Characteristics of included studies table. Further information obtained for Kirkley 1999 confirmed that allocation concealment (item A) was achieved through the use of numbered sealed opaque envelopes opened by an independent person. There was insufficient information to judge whether allocation was concealed in Sandow 1996 (application of Zelen's double consent design) or Wintzell 1999 (use of closed envelopes). Allocation was not concealed in Bottoni 2002, where allocation was based on the last digit of the participant's national security number.

With the exception of Wintzell 1999, there was insufficient information to confirm that intention-to-treat analysis had been carried out (item B). In particular, there was a lack of information on the potential affect of patient choice from the use of Zelen's double consent randomisation design in Sandow 1996. Using this study design, eligible individuals would have been randomised to the surgical or non-surgical group before they gave consent to participate in the trial. The participants would then have been informed of the group to which they had been allocated and offered the opportunity to switch to the other group.

Blinding of outcome assessors (item C) with details of adequate safeguards was reported in Kirkley 1999. None of the other trials referred to assessor blinding although an independent assessor was employed in Wintzell 1999. Blinding of patients and care providers (items $\mathrm{E}$ and F) is unlikely in these comparisons and none was claimed.

Baseline characteristics (item D) were adequately defined and comparable in the two treatment groups in three trials (Bottoni 2002; Kirkley 1999; Wintzell 1999). There were no data available on baseline characteristics in Sandow 1996.

Similarly, only the three trials reported as full publications (Bottoni 2002; Kirkley 1999; Wintzell 1999) provided sufficient information to confirm the comparability of care programmes (item G) and adequately described the intended trial populations (item $\mathrm{H}$ ). The description and application of trial interventions (item I) were satisfactory in Bottoni 2002 and Kirkley 1999, but less satisfactory in Wintzell 1999, where four patients were reported as having a different lavage technique.

The outcome measures used in the trials were generally well defined (item J), the lower score in Sandow 1996 again reflecting a reporting deficiency. The quality of outcome measurement in terms of the appropriateness of the measures used (item K) was acceptable in three trials (Bottoni 2002; Kirkley 1999; Wintzell 1999), but just about adequate in the Sandow 1996. Active follow-up for one year or more (item L) occurred in all four trials.

\section{Effects of interventions}


The main comparison in this review is of any surgical intervention versus conservative treatment. We present analyses for primary and secondary outcome measures subgrouped by the basic type of surgical intervention: namely, arthroscopic stabilisation (Bottoni 2002; Kirkley 1999; Sandow 1996) and arthroscopic lavage (Wintzell 1999). As described above, Sandow 1996 was inadequately reported and percentages were presented rather than exact numbers. Although we have presented the results from this trial in the analyses by making assumptions of the numbers of patients available at follow-up, we consider the findings of Sandow 1996 should be given far less credence than those from the three other trials, which were reported in full journal publications. We undertook sensitivity analyses to see the effect of omitting the results of this trial when pooled data gave a statistical significant result. The data were insufficient to examine differences in basic surgical methods (arthroscopic versus lavage) by indirect comparisons and for other sensitivity analyses testing trial or review methodology.

\section{Primary outcomes}

Different aspects of recovery were reported by four trials. All 24 military personnel in Bottoni 2002 returned to active duty. At longer-term follow-up (mean 79 months), one person in each group of Kirkley 1999 indicated that they had not returned to all or most of their pre-injury sport or activities. Sandow 1996 reported that $10 \%$ of the surgical group versus $90 \%$ of the nonsurgical group failed to attain previous activity levels at sport (extrapolated data: risk ratio (RR) $0.12,95 \%$ confidence interval (CI) 0.03 to 0.44$)$. Similar numbers had substantially reduced sports participation in Wintzell 1999 (RR 0.77, 95\% CI 0.33 to 1.80) and one person in the non-surgical group had changed their occupation at one year. Since the outcome measures in the four trials were very different and the pooled results highly heterogeneous ( $\mathrm{P}$ $\left.=0.04, \mathrm{I}^{2}=69 \%\right)$, Analysis 1.1 shows the results for individual trials only.

Pooled results from all four trials showed that subsequent instability, either redislocation or subluxation, was highly statistically significantly less frequent in the surgical group (see Analysis 1.2: RR $0.25,95 \%$ CI 0.14 to 0.44 ). These results, which pertained to between one-year (Wintzell 1999) and two-year follow-up (Bottoni 2002; Kirkley 1999), were consistent. However, there was some indication of moderate heterogeneity $\left(\mathrm{I}^{2}=43 \%\right.$ for the arthroscopic repair group) which resulted from the inclusion of the results of Kirkley 1999. Removal of the data for Sandow 1996 resulted in a reduction from a four to a three fold difference in recurrent instability; this result remained highly statistically significant (see Analysis 1.3: RR 0.32, 95\% CI 0.17 to 0.59). Both Kirkley 1999 and Wintzell 1999 found that redislocation occurred later in the surgical group; Wintzell 1999 also reported that fewer redislocations were sustained by individuals in the surgical group (mean number: 1.3 versus 3.3). Longer-term follow-up at a mean of 79 months for Kirkley 1999 found there had been no further redislo- cations after 24 months. The three trials reporting on subsequent surgery for instability showed this occurred significantly less often in the surgical group (see Analysis 1.4: RR 0.22, 95\% CI 0.08 to 0.64). Open Bankart stabilisation was performed in all seven cases in Bottoni 2002; the type of surgery chosen for stabilisation was not described in Kirkley 1999 or Wintzell 1999. Sandow 1996 reported that one surgical group patient versus 10 non-surgical group patients required open stabilisation, but did not confirm whether these operations took place.

No trial reported on persistent or long-term pain nor gave discrete data on subjectively-reported instability.

Patient-rated functional assessment measures for the shoulder were recorded in Bottoni 2002, which used the Single Assessment Numeric Evaluation (SANE) method (Williams 1999) and L'Insalata shoulder evaluation (L'Insalata 1997), and Kirkley 1999, which primarily used the Western Ontario Shoulder Instability (WOSI) index (Kirkley 1998). Combined clinical and patient assessment tools for the shoulder were used in Wintzell 1999, which applied the Rowe shoulder score (Rowe 1978). The differences between the two groups in Bottoni 2002 in the mean SANE (88 versus 57) and L'Insalata scores ( 94 versus 73 ) in favour of surgical treatment were reported as statistically significant (reported P $<0.002$ in both cases). As shown in Analysis 1.5, the overall WOSI score (mean difference $-346.92,95 \%$ CI is -625.44 to -68.40 ) as well as the scores for each of the four component domains were statistically significantly better in the surgical treatment group at 32 months in Kirkley 1999. At 79 months follow-up in 31 people, the difference in the overall WOSI score (mean difference -241.50, 95\% CI -566.77 to 83.77 ) was no longer statistically significant (see Analysis 1.6), though still favouring the surgical group. Significantly fewer surgical group patients had an unsatisfactory Rowe grade in Wintzell 1999 (see Analysis 1.7: RR 0.33, 95\% CI 0.15 to 0.72 ).

\section{Secondary outcomes}

Objective instability, defined as a positive apprehension test, was significantly less common in participants of the surgical group in the only trial (Wintzell 1999) reporting this outcome (see Analysis 1.8: RR $0.41,95 \%$ CI 0.20 to 0.85 ).

There were no data pertaining to stiffness nor muscle strength. Range of movement was reported by all four trials but only for subgroups in Sandow 1996 and Wintzell 1999. Bottoni 2002 found a similar average loss of external rotation in the two groups ( 4 versus 3 degrees). Of the five range of movement measures in Kirkley 1999, only the difference in forward flexion reached statistical significance (see Analysis 1.9: mean difference $-4.56 \%$, $95 \%$ CI $-8.99 \%$ to $0.13 \%$ of normal side). The clinical significance of this difference is uncertain and Kirkley 1999 focused on the trend (mean difference 12.7\%) for a limitation of external rotation in the surgical group (see Analysis 1.9), which they considered might be protective. The difference in the mean spine level (T6 
versus T5) reached when putting the hand up the backbone was reported as not being statistically significant.

Aside from a septic joint in one patient who had arthroscopic stabilisation in Kirkley 1999, there were no other treatment complications reported by Bottoni 2002, Kirkley 1999 or Wintzell 1999 (see Analysis 1.10). It should be noted, however, that we have assumed that the lack of information about treatment complications in the non-surgical groups of Bottoni 2002 and Wintzell 1999 meant that there were none to report. Long-term complications, such as osteoarthritis, were not reported.

Pooled results from the two arthroscopic repair trials (Bottoni 2002; Sandow 1996) recording patient satisfaction showed significantly fewer surgical group patients expressed dissatisfaction with the results of their treatment (see Analysis 1.11: RR 0.21, 95\% CI 0.07 to 0.64$)$.

None of the reports provided quantitative information on service utilisation or resource use; for instance, on the length of hospital stay, outpatient attendance or the costs of the provision of physiotherapy.

\section{DISCUSSION}

This review includes evidence from only four small trials, involving a total of 163 participants. Though our search for trials was comprehensive and systematic, it is possible that we have failed to locate other trials. Reassuringly, other systematic reviews (Brody 2009) have not located any other randomised trials. We were unsuccessful in our attempts to obtain further details for Sandow 1996 which was presented only in conference abstracts. The validity of the available data for this trial remains in question, and we made some allowance for this in our analyses. There is also a potential for systematic bias to impinge on the validity of the evidence from the other included trials, for example, effective concealment of treatment allocation was not confirmed for Wintzell 1999, and Bottoni 2002 was quasi randomised. Overall, there is a need for a cautious interpretation of the available evidence.

In the first version of this review we included a trial (Jakobsen 1996) which was subsequently excluded when a full report, which included a detailed description of the interventions, of the 10year follow-up results was published (Jakobsen 2007). Our general caution regarding trials reported in abstract only is thus even more pertinent. Although other reviews (Brody 2009; Padua 2007) and articles (Cox 2008; Mohtadi 2007) on this topic have viewed Jakobsen 2007 as a trial comparing surgery (repair) versus conservative or non-operative treatment, the inclusion criteria of our review exclude it because all its participants underwent diagnostic arthroscopy. .

Though the overall numbers were small, the populations of the four trials were similar. All trial participants had sustained a primary acute traumatic anterior shoulder dislocation and the ma- jority of participants were young (generally early 20s) very active people, usually male, who are in the highest category for recurrence (Hovelius 1996). These similarities in the trial populations support the pooling of compatible outcome measures from the four trials.

\section{Applicability of the evidence}

Given the specific characteristics of the trial populations, we consider that it would be inappropriate to generalise the findings to a general population or to age groups or people with activity levels that differ from those in the included trials.

Though all four trials compared surgical versus non-surgical treatment, the types of surgery (arthroscopic repair using different materials; arthroscopic lavage) differed, as did the duration of sling immobilisation and rehabilitation. While we presented subgroup analyses by surgical treatment type, this review only addresses the general question of 'any' surgery versus 'any' non-surgical treatment. It does not enable identification of the 'best' surgical treatment or of the 'best' conservative treatment. Nor does it compare 'best' surgical with 'best' non-surgical treatment. As well as advances in surgical treatment, the potential for important advances in non-surgical treatment that improve shoulder stability cannot be dismissed. While currently the review comparing different conservative interventions including rehabilitation (Handoll 2006) is inconclusive, post-reduction immobilisation with the arm in external as compared with internal rotation is the subject of much ongoing research.

The results of the four trials were consistently more favourable in the surgically treated group. Surgery significantly reduced subsequent instability, a finding that remained significant even after omission of the results of the incompletely reported trial (Sandow 1996). Half (17/33) of the non-surgically treated trial participants with shoulder instability in the three fully reported trials opted for subsequent surgery. Though different functional assessment measures for the shoulder were recorded in the four trials, the results were more favourable, usually statistically significantly so, in the surgical treatment groups. This and the low incidence of complications (just one septic joint) provide some evidence that existing methods of surgery may improve functional recovery. It may allow a better and more lasting return to demanding physical activity as in military training or strenuous sports participation.

There are four key questions that need consideration before adopting surgery as the recommended treatment, even for this specific category of patient.

\section{Is the evidence reliable?}

We think it probably is but with serious reservations. Three of the four included studies had important methodological flaws which may have introduced bias. Assessor blinding was only done in one trial (Kirkley 1999) and participant and care-provider blinding 
would have been impractical. The sample sizes were small and thus susceptible to random bias. Nonetheless the outcomes of the four trials were consistent with each other, and with other evidence (e.g. DeBerardino 2001a; Kim 2003) that shows surgery helps to prevent the very high rate of dislocation associated with conservative treatment in this particularly high-risk group. Importantly, there was some reassuring evidence about functional outcome; and some functional assessment was based on validated patient-rated measures. Though there was some evidence of a more favourable functional outcome in the surgically treated group this needs confirmation.

\section{Should we wait for a recurrence before considering surgery?}

This is generally what happens now as shown by a recent survey conducted in the UK (Freudmann 2004). Nonetheless, as shown by the focus of the four included trials and often highlighted elsewhere, this is a key area of controversy in the treatment of these injuries (Hawkins 1991). The trials recruited the population at highest risk of recurrence and further tissue damage; this increases the attraction of primary surgery, provided it is shown to be safe and effective in preventing instability and restoring pain-free function. It should be noted, however, that some shoulder instability also occurred in the surgical treatment group and also that, in the three fully reported trials, only half those with recurrence in the conservative treatment group chose or underwent subsequent surgery.

\section{Does surgery affect long-term outcome?}

We do not know. The longer-term follow-up report, in a conference abstract, of Kirkley 1999 gave some reassuring functional results at 79 months but for a reduced trial population. The other included studies did not address this outcome. There remains a need to establish whether surgery affects the development of osteoarthritis or other chronic shoulder disorders. These are also likely to depend on the type of surgery and underlying pathology.

\section{Could and should primary surgery for this high risk age group be implemented?}

It is instructive to consider how the study populations could differ from the usual population and also what could be done or made available in practice. The participants of Bottoni 2002 were activeduty military personnel who would require a very high level of fitness and functioning to perform their job; these, like professional athletes, would be expected to exercise to a higher level, intensity and duration than the majority of patients attending accident and emergency departments. Likewise, all trial participants were probably athletes in Sandow 1996. Though generally conducted in university hospitals, the other two trials covered more general populations. The majority had received their injuries during sports activities in Kirkley 1999 (70\%) and Wintzell 1999 (62\%). It is still likely that the majority of people in the age group of these trials are physically very active though a distinction, perhaps in terms of motivation, can be made for those whose occupation or sports aspirations depends on a highly functioning and stable shoulder. Perhaps some indicators for a higher patient motivation can also be drawn from the actual participation in these trials.

There was no information on service utilisation or resource use in the four trials. A recent assessment of the practicality of offering arthroscopic lavage to young ( 15 to 22 age group) patients with primary traumatic anterior dislocation in a UK hospital setting concluded that offering this to these patients within 10 days of injury was "manageable within our current trauma service arrangements" (Davy 2002). This study also stressed that "such intervention must be both appropriate and acceptable to the patient" and referred to plans for a randomised trial comparing arthroscopic lavage with joint aspiration (suction to remove fluid) in this patient group.

\section{AUTHORS' CONCLUSIONS}

\section{Implications for practice}

While limited, the available evidence from randomised controlled trials supports primary surgery in young adults (usually male) engaged in highly demanding physical activities who have sustained their first acute traumatic shoulder dislocation. No guidance on the best method of surgery can be provided by this review. There is no evidence available to determine whether surgical or non-surgical treatment is better for other categories of patient or injury. In particular, whether non-surgical treatment should not remain the prime treatment option after primary dislocation in those who are at a much lower risk of redislocation.

\section{Implications for research}

There is a need for sufficiently powered, high quality and appropriately reported randomised trials of good standard surgical intervention versus good standard conservative treatment for primary anterior shoulder dislocation. As well as for the patient category included in the present trials, trials including other patient categories at lower risk of recurrence are also warranted. Future research should focus on obtaining sufficiently long-term follow-up (ideally five years or more) on all patients using a systematic and prospective approach to document all possible late complications such as painful shoulder, late instability or osteoarthritis. Attention should be given to outcome assessment in future trials. The use of well-defined and validated functional outcome measures, including patient-derived quality of life measures, is preferable. In addition, while blinding of interventions is not easy to do, concealed 
allocation should be done and, where possible, blinded outcome measurement as these would improve the quality and validity of future results.

The availability of the systematic review comparing different surgical interventions for instability (Pulavarti 2009) as well as the updating of the systematic review comparing different conservative interventions including rehabilitation (Handoll 2006) should provide important information in this area.

\section{ACKNOWLEDGEMENTS}

We thank Lesley Gillespie for developing the subject-specific search strategy for MEDLINE, supplying paper copies of some of the trial reports, for correcting the references and general help at editorial review of the first update, and for updating the search and providing advice on reporting the search for the third update. We thank Amy Kavanagh for providing paper copies of articles. We thank the following for helpful comments at editorial and external review of the protocol or review, or both: Bill Gillespie, Lesley Gillespie, Peter Herbison, Tracey Howe, Rajan Madhok, Julie McBirnie, Marc Swiontkowski and Janet Wale. We thank Amar Rangan for his contribution to the first version of the review.

\section{REFERENCE S}

\section{References to studies included in this review}

\section{Bottoni 2002 \{published data only\}}

Bottoni CR, Wilckens JH, DeBerardino TM, D'Alleyrand JG, Rooney RC, Harpstrite JK, et al.A prospective, randomized evaluation of arthroscopic stabilization versus nonoperative treatment of acute, traumatic, first-time shoulder dislocations. In: Annual Meeting of the American Academy of Orthopaedic Surgeons; 2001 Feb 28-Mar 4; San Francisco (CA). http:// www.aaos.org/wordhtml/anmt2001/sciprog/201.htm (accessed 13/03/03).

* Bottoni CR, Wilckens JH, DeBerardino TM, D'Alleyrand JG, Rooney RC, Harpstrite JK, et al.A prospective, randomized evaluation of arthroscopic stabilization versus nonoperative treatment in patients with acute, traumatic, first-time shoulder dislocations. American Journal of Sports Medicine 2002;30(4): 576-80.

Kirkley 1999 \{published and unpublished data\}

Edmonds G, Kirkley A, Birmingham TB, Fowler PJ. The effect of early arthroscopic stabilization compared to nonsurgical treatment on proprioception after primary traumatic anterior dislocation of the shoulder. Knee Surgery, Sports Traumatology, Arthroscopy 2003; 11(2):116-21.

Griffin S. personal communication February 182005.

Kirkley A, Edmonds G, Fowler PJ. The effect of early arthroscopic stabilization compared to immobilization and rehabilitation on proprioception of the shoulder after primary traumatic anterior dislocation [abstract]. Journal of Bone and Joint Surgery. British Volume 1998;80 Suppl 1:16.

Kirkley A, Griffin S, Miniaci A, Mohtadi N. Prospective randomized clinical trial comparing the effectiveness of immediate arthroscopic stabilization versus immobilization and rehabilitation in first traumatic anterior dislocations of the shoulder [abstract]. Journal of Bone and Joint Surgery. British Volume 2000;82 Suppl 2 157.

Kirkley A, Griffin S, Miniaci A, Mohtadi N. Prospective randomized clinical trial comparing the effectiveness of immediate arthroscopic stabilization versus immobilization and rehabilitation in first traumatic anterior dislocations of the shoulder [abstract]. Journal of Shoulder and Elbow Surgery 1999;8(2):181.

* Kirkley A, Griffin S, Richards C, Miniaci A, Mohtadi N. Prospective randomized clinical trial comparing the effectiveness of immediate arthroscopic stabilization versus immobilization and rehabilitation in first traumatic anterior dislocations of the shoulder. Arthroscopy 1999;15(5):507-14.

Kirkley A, Griffin S, Richards C, Miniaci A, Mohtadi N. Prospective randomized clinical trial comparing the effectiveness of immediate arthroscopic stabilization versus immobilization and rehabilitation in first traumatic anterior dislocations of the shoulder [abstract]. Orthopaedic Transactions 1998;22(2):427.

Kirkley A, Griffin S, Richards C, Mohtadi N, Miniaci A.

Prospective randomised clinical trial comparing the effectiveness of 
immediate arthroscopic stabilization versus immobilization and rehabilitation in first traumatic anterior dislocations of the shoulder [abstract]. Clinical Journal of Sport Medicine 1997;7:242. Kirkley A, Griffin S, Werstine R, Rajtek A. Prospective RCT comparing the effectiveness of surgical versus non-surgical treatment in first traumatic anterior dislocations of the shoulder: Evaluation of long-term QOL. In: American Orthopaedic Society for Sports Medicine. 2002 Specialty Day; 2002 Feb 16; Dallas (Texas). Available at http://www.sportsmed.org/Meetings/CME/ Default.htm (accessed 02/04/03).

Kirkley A, Griffin SA, Richards C, Miniaci A, Mohtadi N. Prospective randomized clinical trial comparing the effectiveness of immediate arthroscopic stabilization versus immobilization and rehabilitation in first traumatic anterior dislocations of the shoulder [abstract]. Journal of Bone and Joint Surgery. British Volume 1998; 80 Suppl 1:15-6.

Kirkley A, Werstine R, Ratjek A, Griffin S. Prospective randomized clinical trial comparing the effectiveness of immediate arthroscopic stabilization versus immobilization and rehabilitation in first traumatic anterior dislocations of the shoulder: Long-term evaluation. Arthroscopy 2005;21(1):55-63.

Litchfield R, Kirkley A, Ehrensberger E, Spouge A, Thain L. MRI as a predictor of surgical pathology in primary anterior dislocations of the shoulder [abstract]. Orthopaedic Transactions 1996;20(1):79.

\section{Sandow 1996 \{published data only\}}

* Sandow M, Liu SH. Acute arthroscopic Bankart repair for initial anterior shoulder dislocation: A prospective clinical trial [abstract]. Journal of Shoulder and Elbow Surgery 1996;5(2):581.

Sandow MJ. Arthroscopic repair for primary shoulder dislocation: A randomized clinical trial [abstract]. Journal of Bone and Joint Surgery. British Volume 1995;77(Suppl 1):67.

\section{Wintzell 1999 \{published data only\}}

* Wintzell G, Haglund-Akerlind Y, Ekelund A, Sandstrom B, Hovelius L, Larsson S. Arthroscopic lavage reduced the recurrence rate following primary anterior shoulder dislocation. A randomised multicentre study with 1-year follow-up. Knee Surgery Sports Traumatology Arthroscopy 1999;7(3):192-6.

Wintzell G, Haglund Akerlind Y, Novak J, Larsson S. Arthroscopic lavage compared with nonoperative treatment for traumatic primary anterior shoulder dislocation: A 2-year follow-up of a prospective randomized study. Journal of Shoulder and Elbow Surgery 1999;8(5):399-402.

Wintzell G, Haglund-Akerlind Y, Tengvar M, Johansson L, Eriksson E. MRI examination of the glenohumeral joint after traumatic primary anterior dislocation. A descriptive evaluation of the acute lesion and at 6-month follow-up. Knee Surgery Sports Traumatology Arthroscopy 1996;4(4):232-6.

Wintzell G, Haglund Akerlind Y, Tidermark J, Wredmark T, Eriksson E. A prospective controlled randomized study of arthroscopic lavage in acute primary anterior dislocation of the shoulder: one-year follow-up. Knee Surgery Sports Traumatology Arthroscopy 1996;4(1):43-7.

Wintzell G, Haglund Y, Tidermark J, Wredmark T, Eriksson E. Arthroscopic lavage in acute traumatic primary anterior dislocation of the shoulder. A prospective randomised study [abstract]. Surgery of the Shoulder: Proceedings of the 6th International Congress on
Surgery of the Shoulder; 1995 June 27-July 1 and 2-4 July; Helsinki and Stockholm. Elsevier Science, 1995:225. Wintzell G, Hovelius L, Wikblad L, Saebo M, Larsson S. Arthroscopic lavage speeds reduction in effusion in the glenohumeral joint after primary anterior shoulder dislocation: a controlled randomized ultrasound study. Knee Surgery Sports Traumatology Arthroscopy 2000;8(1):56-60.

\section{References to studies excluded from this review}

\section{Arciero 1994 \{published data only\}}

Arciero RA, Wheeler JH, Ryan JB, McBride JT. Arthroscopic Bankart repair versus nonoperative treatment for acute, initial anterior shoulder dislocations. American Journal of Sports Medicine 1994;22(5):589-94.

\section{DeBerardino 2001 \{published data only\}}

DeBerardino TM, Arciero RA, Taylor DC, Uhorchak JM.

Prospective evaluation of arthroscopic stabilization of acute, initial anterior shoulder dislocations in young athletes. Two- to five-year follow-up. American Journal of Sports Medicine 2001;29(5):586-92.

\section{Jakobsen 1996 \{published data only\}}

Jakobsen BW. personal communication June 212004.

* Jakobsen BW, Johannsen HV, Suder P, Sojbjerg JO. Primary

repair versus conservative treatment of first-time traumatic anterior dislocation of the shoulder: a randomized study with 10-year follow-up. Arthroscopy 2007;23(2):118-23.

Jakobsen BW, Sojberg JO. Primary repair after traumatic anterior dislocation of the shoulder joint [abstract]. Orthopaedic Transactions 1997;21(4):1259-60.

Jakobsen BW, Sojbjerg JO. Primary repair after traumatic anterior dislocation of the shoulder joint [abstract]. Acta Orthopaedica Scandinavica. Supplementum 1996;272:13.

Suder P, Jakobsen B, Danish Society for Shoulder and Elbow Surgery. Results of conservative treatment of traumatic primary anterior shoulder dislocation correlated to initial arthroscopic findings - a prospective study of 39 young patients [abstract]. Acta Orthopaedica Scandinavica. Supplementum 1997;274:33. Suder P, Jakobsen BW. The prognostic value of the Baker classification of recurrence after traumatic primary anterior shoulder dislocation in conservatively treated patients [abstract]. Acta Orthopaedica Scandinavica. Supplementum 1997;277:22.

Kulkarni 2003 \{published data only\} Kulkarni R. Welsh acute shoulder dislocation project. National Research Register (NRR) Archive. Available from https:// portal.nihr.ac.uk/Profiles/NRR.aspx? Publication ID=M0054049707. [: NRR ID: M0054049707]

\section{Robinson 2008 \{published data only\}}

Helms K. Traumatic first-time anterior dislocation of the shoulder How should it be treated? [Vordere schulterluxation: Traumatische erstluxation der Schulter - Was soll man tun?]. Zeitschrift fur Orthopadie und Unfallchirurgie 2008;146(3):301. [EMBASE: 2008363257]

* Robinson CM, Jenkins PJ, White TO, Ker A, Will E. Primary arthroscopic stabilization for a first-time anterior dislocation of the shoulder. A randomized, double-blind trial. Journal of Bone \& Joint Surgery. American Volume 2008;90(4):708-21.

White T. Acute shoulder stabilisation using endoscopic techniques ASSET. National Research Register (NRR) Archive. Available from 
https://portal.nihr.ac.uk/Profiles/NRR.aspx?

Publication'ID=N0519110939.

\section{Trimmings 1985 \{published data only\}}

Trimmings NP. Haemarthrosis aspiration in treatment of anterior dislocation of the shoulder. Journal of the Royal Society of Medicine 1985;78(12):1023-7.

\section{Yanmis 2003 \{published and unpublished data\}}

Yanmis I, Tunay S, Komurcu M, Yildiz C, Tunay VB, Gur E. Outcomes of acute arthroscopic repair and conservative treatment following first traumatic dislocation of the shoulder joint in young patients. Annals of the Academy of Medicine, Singapore 2003;32(6): $824-7$.

\section{Additional references}

\section{Altman 2003}

Altman DG, Bland JM. Interaction revisited: the difference between two estimates. BMJ 2003;326(7382):219.

\section{Bankart 1938}

Bankart AS. The pathology and treatment of recurrent dislocation of the shoulder joint. British Journal of Surgery 1938;26(101):23-9.

\section{Brody 2009}

Brophy RH, Marx RG. The treatment of traumatic anterior instability of the shoulder: nonoperative and surgical treatment. Arthroscopy 2009;25(3):298-304.

\section{Cox 2008}

Cox CL, Kuhn JE. Operative versus nonoperative treatment of acute shoulder dislocation in the athlete. Current Sports Medicine Reports 2008;7(5):263-8.

\section{Davy 2002}

Davy AR, Drew SJ. Management of shoulder dislocation - are we doing enough to reduce the risk of recurrence?. Injury 2002;33(9): 775-9.

\section{De Palma 1983}

De Palma AF. Surgery of the shoulder. 3rd Edition. Philadelphia: Lippincott, 1983. [: ISBN:0397504926]

\section{DeBerardino 2001a}

DeBerardino TM, Arciero RA, Taylor DC, Uhorchak JM.

Prospective evaluation of arthroscopic stabilization of acute, initial anterior shoulder dislocations in young athletes. Two- to five-year follow-up. American Journal of Sports Medicine 2001;29(5):586-92.

\section{Fleega 1991}

Fleega B. Operation for a recurrent dislocation. In: Watson MS editor(s). Surgical disorders of the shoulder. Edinburgh: Churchill Livingstone, 1991:339-51. [: ISBN: 0443038899]

Freudmann 2004

Freudmann M, Hay S. The UK shoulder surgeon's approach to traumatic, anterior shoulder dislocation in young patient [abstract]. Journal of Bone and Joint Surgery. British Volume 2004;86(Suppl 1): 98.

\section{Goss 1988}

Goss TP. Anterior glenohumeral instability. Orthopedics 1988;11 (1):87-95.

\section{Handoll 2006}

Handoll HHG, Hanchard NCA, Goodchild L, Feary J.

Conservative management following closed reduction of traumatic anterior dislocation of the shoulder. Cochrane Database of Systematic Reviews 2006, Issue 1. [DOI: 10.1002/

14651858.CD004962.pub2]

\section{Hawkins 1991}

Hawkins RJ, Mohtadi GH. Controversy in anterior shoulder instability. Clinical Orthopedics and Related Research 1991;(272): 152-61.

\section{Helms 2008}

Helms K. Traumatic first-time anterior dislocation of the shoulder How should it be treated? [Vordere schulterluxation: Traumatische erstluxation der Schulter - Was soll man tun?]. Zeitschrift fur Orthopadie und Unfallchirurgie 2008;146(3):301. [EMBASE: 2008363257]

\section{Higgins 2003}

Higgins JP, Thompson SG, Deeks JJ, Altman DG. Measuring inconsistency in meta-analyses. BMJ 2003;327(7414):557-60.

\section{Higgins 2006}

Higgins JPT, Green S, editors. Highly sensitive search strategies for identifying reports of randomized controlled trials in MEDLINE. Cochrane Handbook for Systematic Reviews of Interventions 4.2.6 [updated September 2006]; Appendix 5b. Available from www.cochrane.org/resources/handbook/ Handbook4.2.6Sep2006.pdf.

\section{Hill 1940}

Hill HA, Sachs MD. The grooved defect of the humeral head: A frequently unrecognised complication of dislocations of the shoulder joint. Radiology 1940;35:690-700.

\section{Hovelius 1982}

Hovelius L. Incidence of shoulder dislocation in Sweden. Clinical Orthopaedics and Related Research 1982;(166):127-31.

\section{Hovelius 1996}

Hovelius L, Augustini BG, Fredin H, Johansson O, Norlin R, Thorling J. Primary anterior shoulder dislocation of the shoulder in young patients. Journal of Bone and Joint Surgery. American Volume 1996;78(11):1677-84.

\section{Jakobsen 2007}

Jakobsen BW, Johannsen HV, Suder P, Sojbjerg JO. Primary repair versus conservative treatment of first-time traumatic anterior dislocation of the shoulder: a randomized study with 10-year follow-up. Arthroscopy 2007;23(2):118-23.

\section{Kazar 1969}

Kazar B, Relovsky E. Prognosis of primary dislocation of the shoulder. Acta Orthopaedica Scandinavica 1969;40(2):216-24.

Kim 2003

Kim SH, Ha KI, Cho YB, Ryu BD, Oh I. Arthroscopic anterior stabilization of the shoulder: two to six-year follow-up. Journal of Bone \& Joint Surgery. American Volume 2003;85(8):1511-8.

Kirkley 1997

Kirkley A, Griffin S, Richards C, Mohtadi N, Miniaci A. Prospective randomised clinical trial comparing the effectiveness of immediate arthroscopic stabilization versus immobilization and rehabilitation in first traumatic anterior dislocations of the shoulder [abstract]. Clinical Journal of Sport Medicine 1997;7:242. 


\section{Kirkley 1998}

Kirkley A, Griffin S, McLintock H, Ng L. The development and evaluation of a disease-specific quality of life measurement tool for shoulder instability. American Journal of Sports Medicine 1998;26 (6):764-72.

L'Insalata 1997

L'Insalata JC, Warren RF, Cohen SB, Altchek DW, Peterson MG. A self-administered questionnaire for assessment of symptoms and function of the shoulder. The Western Ontario Shoulder Instability Index (WOSI). Journal of Bone and Joint Surgery. American Volume 1997;79(5):738-48. [MEDLINE: 9160947]

Mohtadi 2007

Mohtadi N. Open repair reduced recurrent dislocation more than conservative treatment after traumatic anterior shoulder dislocation [commentary]. Journal of Bone and Joint Surgery. American Volume 2007;89(8): 1871.

Morrey 1981

Morrey BF, Chao EX. Recurrent anterior dislocation of the shoulder. In: Black J, Dumbleton JH editor(s). Clinical biomechanics: a case history approach. New York: Churchill Livingstone, 1981:24-46. [: ISBN - 0443080224]

\section{O'Brien 1987}

O’Brien SJ, Warren RF, Schwartz EA. Anterior shoulder instability. Orthopedic Clinics of North America 1987;18(3):395-408.

\section{Padua 2007}

Padua R, Bondi R, Bondi L, Campi A. Surgical versus conservative treatment for acute first-time anterior shoulder dislocation: The evidence. Journal of Orthopaedics and Traumatology 2007;8(4): $207-13$.

\section{Pulavarti 2009}

Pulavarti RS, Symes TH, Rangan A. Surgical interventions for anterior shoulder instability in adults. Cochrane Database of
Systematic Reviews 2009, Issue 4. [DOI: 10.1002/

14651858.CD005077.pub2]

\section{Rowe 1956}

Rowe CR. Prognosis in dislocation of the shoulder. Journal of Bone and Joint Surgery. American Volume 1956;38(5):957-77.

Rowe 1978

Rowe CR, Patel D, Southmayd WW. The Bankart procedure: a long-term end-result study. Journal of Bone and Joint Surgery. American Volume 1978;60(1):1-16.

\section{Simonet 1984}

Simonet WT, Melton LJ II, Cofield RH, Ilstrup DM. Incidence of anterior shoulder dislocation in Olmsted County, Minnesota. Clinical Orthopaedics and Related Research 1984;(186):186-91.

\section{White 2003}

White T. Acute shoulder stabilisation using endoscopic techniques ASSET. National Research Register (NRR) Archive. Available from https://portal.nihr.ac.uk/Profiles/NRR.aspx? Publication $\cdot$ ID=N0519110939.

Williams 1999

Williams GN, Gangel TJ, Arciero RA, Uhorchak JM, Taylor DC. Comparison of the Single Assessment Numeric Evaluation method and two shoulder rating scales. Outcomes measures after shoulder surgery. American Journal of Sports Medicine 1999;27(2):214-21.

\section{References to other published versions of this review}

\section{Handoll 2004}

Handoll HH, Al-Maiyah MA, Rangan A. Surgical versus nonsurgical treatment for acute anterior shoulder dislocation. Cochrane Database of Systematic Reviews 2004, Issue 1. [DOI: 10.1002/ 14651858.CD004325.pub2]

* Indicates the major publication for the study 
CHARACTERISTICS OF STUDIES

\section{Characteristics of included studies [ordered by study ID]}

Bottoni 2002

\begin{tabular}{|c|c|}
\hline Methods & $\begin{array}{l}\text { Randomisation method: quasi-randomised based on odd and even social security numbers. } \\
\text { Assessor blinding: no. } \\
\text { Loss to follow-up: } 3 \text { (12.5\%). } \\
\text { Intention-to-treat analysis: likely. }\end{array}$ \\
\hline Participants & $\begin{array}{l}\text { US Army Medical Centre, Honolulu, Hawaii, USA } \\
24 \text { active-duty personnel (all males) with primary traumatic shoulder dislocation referred to or- } \\
\text { thopaedic clinic within } 48 \text { hours of reduction. } \\
\text { Age range } 18 \text { to } 26 \text { years (mean age } 22 \text { years). } \\
\text { Exclusion criteria: tuberosity or other concomitant fracture, neurological injury, history of shoulder } \\
\text { injury, previous subluxation, or dead arm syndrome. }\end{array}$ \\
\hline Interventions & $\begin{array}{l}\text { Period of study: November } 1994 \text { to April } 1998 \\
\text { Each patient had manual reduction of dislocation and MRI scan. } \\
\text { 1. Surgical: surgery within } 10 \text { days of injury. Interscalene and general anaesthesia. Arthroscopic } \\
\text { Bankart repair after systematic diagnostic arthroscopy. Use of bioabsorbable tack ( } 2 \text { or } 3 \text { used), then } \\
4 \text { weeks in sling followed by supervised rehabilitation. } \\
\text { 2. Non-surgical: four weeks in sling, and supervised rehabilitation. } \\
\text { Both groups had same therapist-supervised 3-phase rehabilitation programme comprising: } \\
\text { 1. During } 4 \text { weeks sling immobilisation, limited active ROM and some exercises under physiother- } \\
\text { apist supervision; } \\
\text { 2. then } 4 \text { weeks of progressive passive motion exercises followed by active-assisted ROM exercises } \\
\text { without resistance } \\
\text { 3. then } 4 \text { weeks of progressively greater resistance exercises to restore active ROM. Return to full } \\
\text { active duty, contact sports and activities requiring over-head or heavy lifting restricted until } 4 \\
\text { months "post-op". } \\
\text { Assigned: } 10 / 14 \\
\text { Analysed: } 9 / 12\end{array}$ \\
\hline Outcomes & $\begin{array}{l}\text { Length of follow-up: minimum } 24 \text { months claimed (ranged } 16-56 \text { months). Assessed: weekly } \\
\text { during first } 8 \text { weeks, monthly until } 6 \text { months, then each } 6 \text { months. } \\
\text { 1. Return to active military duty. } \\
\text { 2. Treatment failure: recurrence, symptomatic subluxation or instability, prevention return to full } \\
\text { activity duty or requiring additional surgical stabilisation. } \\
\text { 3. Additional/subsequent surgical stabilisation. } \\
\text { 4. Shoulder assessment scoring systems: SANE (Single Assessment Numeric Evaluation)and } \\
\text { L'Insalata. } \\
\text { 5. Range of movement. } \\
\text { 6. Complications: intra-operative, reactive synovitis ( } 0 \text { in surgery group). } \\
\text { 7. Satisfaction. }\end{array}$ \\
\hline Notes & \\
\hline
\end{tabular}

Risk of bias

Surgical versus non-surgical treatment for acute anterior shoulder dislocation (Review) 
Bottoni 2002 (Continued)

\begin{tabular}{lll}
\hline Item & Authors' judgement & Description \\
\hline Adequate sequence generation? & No & $\begin{array}{l}\text { Quasi-randomised based on odd and even social } \\
\text { security numbers. }\end{array}$ \\
\hline Allocation concealment? & No & $\begin{array}{l}\text { Allocation based on odd and even social security } \\
\text { numbers. }\end{array}$ \\
\hline
\end{tabular}

\section{Kirkley 1999}

\begin{tabular}{|c|c|}
\hline Methods & $\begin{array}{l}\text { Randomisation method: use of sealed, numbered and opaque envelopes that were opened in the } \\
\text { operating room by the "circulating" nurse after confirmation that the patient was eligible. Stratified } \\
\text { by age (<22 years; } 23 \text { to } 30 \text { years) and surgeon. } \\
\text { Assessor blinding: yes (patients asked to conceal shoulder from assessor). } \\
\text { Loss to follow-up: } 2 \text { ( } 5 \% \text { at } 32 \text { months); } 9 \text { ( } 22.5 \% \text { at } 79 \text { months). } \\
\text { Intention-to-treat analysis: very likely and claimed. }\end{array}$ \\
\hline Participants & $\begin{array}{l}\text { Emergency Departments at University of Western Ontario, Ontario and University of Calgary, } \\
\text { Alberta, Canada } \\
40 \text { adults ( } 35 \text { males) with primary traumatic anterior shoulder dislocation. Skeletally mature and } \\
\text { < } 30 \text { years old. Actual range } 16 \text { to } 30 \text { years; mean } 22 \text { years. Mechanism of abduction, external } \\
\text { rotation, with sudden pain in the shoulder. Reduction required or radiograph showing anterior } \\
\text { dislocation. Informed consent including availability for } 5 \text { years follow-up. } \\
\text { Exclusion criteria: associated fracture (e.g. greater tuberosity)except Hill Sacks or Bankart lesion, } \\
\text { history of multidirectional instability (MDI) or evidence of MDI in other shoulder, neurovascular } \\
\text { compromise (e.g. axillary nerve palsy) of affected limb, or unfit for surgery. }\end{array}$ \\
\hline Interventions & $\begin{array}{l}\text { Period of study: not stated } \\
\text { 1. Surgical: surgery within } 4 \text { weeks of injury. Patients mobilised shoulder on their own to prevent } \\
\text { stiff shoulder. General anaesthesia. Arthroscopic stabilisation by transglenoid suturing using K- } \\
\text { wires to repair Bankart lesion. Then } 3 \text { weeks sling immobilisation before rehabilitation programme. } \\
\text { 2. Non-surgical: } 3 \text { weeks sling immobilisation (could remove for bathing and elbow and wrist } \\
\text { mobilisation)then rehabilitation programme. } \\
\text { Both groups had the same staged ( } 4 \text { to } 6 \text { weeks; } 7 \text { to } 8 \text { weeks; } 9 \text { to } 12 \text { weeks) rehabilitation protocol } \\
\text { of progressive exercises, including easing of the restrictions on external rotation, and times for return } \\
\text { to activities: } 3 \text { month for return to non-contact or non-overhead sports; } 4 \text { months for contact } \\
\text { sports. } \\
\text { Assigned: } 19 / 21 \\
\text { Analysed: } 19 / 19 \text { (at } 32 \text { months) } \\
\text { Analysed: } 16 / 15 \text { (at } 79 \text { months) }\end{array}$ \\
\hline Outcomes & $\begin{array}{l}\text { Length of follow-up: main report at average of } 32 \text { months ("for } 2 \text { years or until dislocation"). } \\
\text { Subsequent full report for } 79 \text { months (range } 51 \text { to } 102 \text { months). } \\
\text { Assessed: data for other follow-up times e.g. } 18 \text { and } 75 \text { months, presented in various abstracts. } \\
\text { 1. Long-term return to pre-injury sport/activities. } \\
\text { 2. Redislocation. } \\
\text { 3. Episodes of subluxation. } \\
\text { 4. Instability. }\end{array}$ \\
\hline
\end{tabular}


Kirkley 1999 (Continued)

5. Additional/subsequent surgical stabilisation.

6. Shoulder assessment scoring systems: ASES (American Shoulder and Elbow Surgeons); DASH ( Disabilities of the Arm, Shoulder and Hand); WOSI (Western Ontario Shoulder Instability Index). The latter consists of 4 domains: (a) physical symptoms and pain, (b) sport, recreation and work function, (c) lifestyle and social functioning, and (d) emotional well being.

7. Range of movement.

8. Isokinetic strength.

9. Complications.

10. Proprioception.

Notes

This study has been reported for various follow-up times. The main report that continues to be used in this review presented the 32 months (minimum 24 months) follow-up data.

Full details of the method of randomisation and the data on the WOSI scores at 79 months were provided by Sharon Griffin (February 2005).

Although intention-to-treat analysis may still have occurred, it is notable that the Kirkley 1997 abstract reported 20 being randomised to each group.

\section{Risk of bias}

\begin{tabular}{l|l|l}
\hline Item & Authors' judgement & Description \\
\hline Adequate sequence generation? & Yes & $\begin{array}{l}\text { No information on random sequence generation } \\
\text { but stratified by age }(<22 \text { years; 23 to } 30 \text { years }) \\
\text { and surgeon. }\end{array}$ \\
\hline Allocation concealment? & Yes & $\begin{array}{l}\text { Use of sealed, numbered and opaque envelopes } \\
\text { that were opened in the operating room by the } \\
\text { "circulating" nurse after confirmation that the } \\
\text { patient was eligible. }\end{array}$ \\
\hline
\end{tabular}

\section{Sandow 1996}

\begin{tabular}{ll} 
Methods & $\begin{array}{l}\text { Randomisation method: not stated but used the double consent randomisation design of Zelen. } \\
\text { Assessor blinding: not stated. } \\
\text { Loss to follow-up: probably none. } \\
\text { Intention-to-treat analysis: not known. }\end{array}$ \\
\hline Participants & $\begin{array}{l}\text { Royal Adelaide Hospital and Wakefield Orthopaedic Clinic, Australia and UCLA Medical Center, } \\
\text { USA } \\
39 \text { people }<26 \text { years old with primary traumatic anterior shoulder dislocation. } \\
\text { Age range } 14 \text { to } 26 \text { years. } \\
\text { Exclusion criteria: history of shoulder instability or ligamentous laxity, bony Bankart lesion or } \\
\text { rotator cuff tear (queried if diagnosed at surgery thus post-randomisation exclusion?) }\end{array}$ \\
\hline Interventions & $\begin{array}{l}\text { Period of study: not stated } \\
1 . \text { Surgical: arthroscopic stabilisation using a bio-absorbable implant (Suretac) within } 10 \text { (or 7?) } \\
\text { days of initial dislocation, then sling for } 4 \text { weeks. } \\
\text { 2. Non-surgical: sling for } 4 \text { weeks. }\end{array}$
\end{tabular}




\begin{tabular}{|c|c|c|}
\hline & \multicolumn{2}{|c|}{$\begin{array}{l}\text { Both groups had sling for four weeks, then a standard rehabilitation programme. } \\
\text { Assigned: } 19 / 20 \\
\text { Analysed: } 19 / 20 \text { (? at } 17 \text { months) }\end{array}$} \\
\hline Outcomes & \multicolumn{2}{|c|}{$\begin{array}{l}\text { Length of follow-up: average } 17 \text { months ( } 12-36 \text { months). Also objective assessment: } 3 \text { and } \\
\text { months. } \\
\text { 1. Return to previous level of sport. } \\
\text { 2. Redislocation. } \\
\text { 3. Recurrent instability (dislocation/subluxation). } \\
\text { 4. Subsequent requirement for open surgery. } \\
\text { 5. Range of movement. } \\
\text { 6. Strength. } \\
\text { 7. Satisfaction. }\end{array}$} \\
\hline Notes & \multicolumn{2}{|c|}{$\begin{array}{l}\text { Trial presently reported in two abstracts only. Requests for further information sent to Dr Sandow } \\
\text { in April and September } 2003 .\end{array}$} \\
\hline \multicolumn{3}{|l|}{ Risk of bias } \\
\hline Item & Authors' judgement & Description \\
\hline Adequate sequence generation? & Unclear & $\begin{array}{l}\text { Used the double consent randomised design of } \\
\text { Zelen - no information. }\end{array}$ \\
\hline Allocation concealment? & Unclear & Unclear. \\
\hline
\end{tabular}

Wintzell 1999

\begin{tabular}{ll} 
Methods & $\begin{array}{l}\text { Randomisation method: closed envelopes - consecutive patients entered into trial. } \\
\text { Assessor blinding: not stated but independent assessor. } \\
\text { Loss to follow-up: none. } \\
\text { Intention-to-treat analysis: yes. }\end{array}$ \\
\hline Participants & $\begin{array}{l}\text { Soder Hospital, Stockholm; St Goran's Hospital, Stockholm; Gavle Hospital, Gavle; Uppsala Uni- } \\
\text { versity Hospital, Uppsala, Sweden } \\
60 \text { people ( } 46 \text { males) with primary traumatic anterior shoulder dislocation with clinical and radi- } \\
\text { ological verification of the injury. Aged } 16 \text { to } 30 \text { years. Mean age: } 24 \text { years. } \\
\text { Exclusion criteria: previous problems on affected side, fracture of the greater tubercle, generalised } \\
\text { joint laxity, a bony Bankart lesion }>6 x 15 \text { mm (width and height) on standard anterior-posterior } \\
\text { and lateral X-rays, drug addiction, or non consent. }\end{array}$ \\
\hline Interventions & $\begin{array}{l}\text { Period of study: not stated } \\
\text { In both groups an optional sling was used for } 1 \text { week after reduction of the dislocation under } \\
\text { anaesthesia. } \\
1 . \text { Surgical: arthroscopic (3 portals) lavage performed within } 10 \text { days (mean } 8 \text { days; range } 4-10 \\
\text { days) under general anaesthesia. Patient in the beach-chair position. Lavage was done with volumes } \\
\text { up to } 400 \text { ml isotonic saline solution, utilising a pressure regulated pump. Small pieces of non- } \\
\text { viable debris near the capsulolabral lesion were trimmed when found (10 patients). }\end{array}$
\end{tabular}


Wintzell 1999 (Continued)

2. Non surgical: optional sling for one week followed by free mobilisation without restriction.
Both groups received an identical rehabilitation programme.
Assigned: $30 / 30$
Analysed: $30 / 30$

Risk of bias

\begin{tabular}{l|ll}
\hline Item & Authors' judgement & Description \\
\hline Adequate sequence generation? & Unclear & No information available. \\
\hline Allocation concealment? & Unclear & $\begin{array}{l}\text { No mention of adequate safeguards: closed en- } \\
\text { velopes - consecutive patients entered into trial. }\end{array}$ \\
\hline
\end{tabular}

MRI: Magnetic resonance imaging

ROM: Range of movement

\section{Characteristics of excluded studies [ordered by study ID]}

\begin{tabular}{l|l} 
Arciero 1994 & Not randomised. Patient selected either arthroscopic Bankart suture repair or non operative treatment. \\
\hline DeBerardino 2001 & Not randomised. Patient selected either surgical, mainly arthroscopic repair, or non operative treatment. \\
\hline Jakobsen 1996 & $\begin{array}{l}\text { This randomised trial was included in the first two versions of the review (up to Issue 4, 2007) based on conference } \\
\text { abstract reports. Upon the availability of a full report of this trial (published 2007) with descriptions of the } \\
\text { interventions and their timing, it became clearer that it was not a straightforward comparison of surgical versus } \\
\text { non-surgical treatment. Immediately after diagnostic arthroscopy, which will have included lavage, consenting } \\
\text { patients with an arthroscopically confirmed anterior capsular (Bankart) lesion were randomised to either open }\end{array}$
\end{tabular}




\begin{tabular}{|c|c|}
\hline & $\begin{array}{l}\text { repair (the patient was "redressed")or "conservative" treatment where "only arthroscopy was performed". A } \\
\text { request for further details of the "conservative" invention, specifically whether further lavage was performed, has } \\
\text { been sent to the trial authors. Though presented as a surgical versus conservative treatment trial, where lavage } \\
\text { is termed a conservative primary treatment, this trial is actually comparing different surgical methods and thus } \\
\text { is not in the scope of this review. } \\
\text { Notes } \\
\text { 1. One of the included trials in this review (Wintzell 1999) found arthroscopic lavage resulted in a reduction } \\
\text { of recurrence compared with conservative treatment. } \\
\text { 2. The study results of Jakobsen } 1996 \text { showed a significant reduction in recurrence after surgical (open) stabili- } \\
\text { sation of the Bankart lesion; this is consistent with the findings of the three studies included in this review that } \\
\text { tested arthroscopic stabilisation. }\end{array}$ \\
\hline Kulkarni 2003 & $\begin{array}{l}\text { Trialist indicated that this study comparing operative versus non operative management is presently abandoned } \\
\text { but may be restarted at some stage. }\end{array}$ \\
\hline Robinson 2008 & $\begin{array}{l}\text { This randomised trial compared arthroscopic Bankart repair versus arthroscopic lavage. Not in the scope of this } \\
\text { review. }\end{array}$ \\
\hline Trimmings 1985 & $\begin{array}{l}\text { Not randomised. This study compared haemarthrosis aspiration with non-aspiration in } 28 \text { patients aged over } \\
60 \text { years after reduction of an anterior dislocation of the shoulder. }\end{array}$ \\
\hline Yanmis 2003 & $\begin{array}{l}\text { This was a comparison of arthroscopic surgery versus conservative treatment, and not a randomised trial. The } \\
\text { trialist confirmed that patients selected their treatment. }\end{array}$ \\
\hline
\end{tabular}


DATA AND ANALYSES

Comparison 1. Surgical versus non-surgical treatment

\begin{tabular}{|c|c|c|c|c|}
\hline Outcome or subgroup title & $\begin{array}{l}\text { No. of } \\
\text { studies }\end{array}$ & $\begin{array}{c}\text { No. of } \\
\text { participants }\end{array}$ & Statistical method & Effect size \\
\hline $\begin{array}{l}1 \text { Non return to pre-injury level of } \\
\text { activity }\end{array}$ & 4 & & Risk Ratio (M-H, Fixed, 95\% CI) & Totals not selected \\
\hline 1.1 Arthroscopic repair & 3 & & Risk Ratio (M-H, Fixed, 95\% CI) & Not estimable \\
\hline 1.2 Arthroscopic lavage & 1 & & Risk Ratio (M-H, Fixed, 95\% CI) & Not estimable \\
\hline $\begin{array}{l}2 \text { Instability: redislocation or } \\
\text { subluxation }\end{array}$ & 4 & 158 & Risk Ratio (M-H, Fixed, 95\% CI) & $0.25[0.14,0.44]$ \\
\hline 2.1 Arthroscopic repair & 3 & 98 & Risk Ratio (M-H, Fixed, 95\% CI) & $0.23[0.12,0.45]$ \\
\hline 2.2 Arthroscopic lavage & 1 & 60 & Risk Ratio (M-H, Fixed, 95\% CI) & $0.31[0.11,0.84]$ \\
\hline $\begin{array}{l}3 \text { Instability: redislocation or } \\
\text { subluxation (minus } 1 \text { trial) }\end{array}$ & 3 & 119 & Risk Ratio (M-H, Fixed, 95\% CI) & $0.32[0.17,0.59]$ \\
\hline 3.1 Arthroscopic repair & 2 & 59 & Risk Ratio (M-H, Fixed, 95\% CI) & $0.33[0.15,0.72]$ \\
\hline 3.2 Arthroscopic lavage & 1 & 60 & Risk Ratio (M-H, Fixed, 95\% CI) & $0.31[0.11,0.84]$ \\
\hline $\begin{array}{l}4 \text { Subsequent surgery for } \\
\text { instability }\end{array}$ & 3 & 119 & Risk Ratio (M-H, Fixed, 95\% CI) & $0.22[0.08,0.64]$ \\
\hline 4.1 Arthroscopic repair & 2 & 59 & Risk Ratio (M-H, Fixed, 95\% CI) & $0.26[0.08,0.82]$ \\
\hline 4.2 Arthroscopic lavage & 1 & 60 & Risk Ratio (M-H, Fixed, 95\% CI) & $0.11[0.01,1.98]$ \\
\hline $\begin{array}{l}5 \text { WOSI (Western Ontario } \\
\text { Shoulder Instability Index) } \\
\text { scores at } 32 \text { months }\end{array}$ & 1 & & Mean Difference (IV, Fixed, 95\% CI) & Totals not selected \\
\hline $\begin{array}{l}5.1 \text { Overall score (0: perfect - } \\
\text { 2100: worst) }\end{array}$ & 1 & & Mean Difference (IV, Fixed, 95\% CI) & Not estimable \\
\hline $\begin{array}{l}5.2 \text { Physical symptoms ( } 0 \text { : } \\
\text { perfect - 1000: worst) }\end{array}$ & 1 & & Mean Difference (IV, Fixed, 95\% CI) & Not estimable \\
\hline $\begin{array}{l}5.3 \text { Sport/recreation/work }(0 \text { : } \\
\text { perfect - } 400 \text { : worst })\end{array}$ & 1 & & Mean Difference (IV, Fixed, 95\% CI) & Not estimable \\
\hline $\begin{array}{l}5.4 \text { Lifestyle (0: perfect - } 400 \text { : } \\
\text { worst) }\end{array}$ & 1 & & Mean Difference (IV, Fixed, 95\% CI) & Not estimable \\
\hline $\begin{array}{l}5.5 \text { Emotions (0: perfect - } \\
\text { 300: worst) }\end{array}$ & 1 & & Mean Difference (IV, Fixed, 95\% CI) & Not estimable \\
\hline $\begin{array}{l}6 \text { WOSI (Western Ontario } \\
\text { Shoulder Instability Index) } \\
\text { scores at } 79 \text { months }\end{array}$ & 1 & & Mean Difference (IV, Fixed, 95\% CI) & Totals not selected \\
\hline $\begin{array}{l}6.1 \text { Overall score (0: perfect - } \\
\text { 2100: worst) }\end{array}$ & 1 & & Mean Difference (IV, Fixed, 95\% CI) & Not estimable \\
\hline $\begin{array}{l}\text { 6.2 Physical symptoms ( } 0 \text { : } \\
\text { perfect - 1000: worst) }\end{array}$ & 1 & & Mean Difference (IV, Fixed, 95\% CI) & Not estimable \\
\hline $\begin{array}{l}6.3 \text { Sport/recreation/work }(0 \text { : } \\
\text { perfect - } 400 \text { : worst })\end{array}$ & 1 & & Mean Difference (IV, Fixed, 95\% CI) & Not estimable \\
\hline $\begin{array}{l}6.4 \text { Lifestyle (0: perfect - } 400 \text { : } \\
\text { worst) }\end{array}$ & 1 & & Mean Difference (IV, Fixed, 95\% CI) & Not estimable \\
\hline $\begin{array}{l}\text { 6.5 Emotions (0: perfect - } \\
\text { 300: worst) }\end{array}$ & 1 & & Mean Difference (IV, Fixed, 95\% CI) & Not estimable \\
\hline
\end{tabular}


7 Rowe shoulder score: fair or poor $\quad 1$ score

8 Objective instability: positive $\quad 1$ apprehension test

8.1 Arthroscopic repair 0

8.2 Arthroscopic lavage

9 Range of movement: \% of normal side

9.1 Forward flexion

9.2 External rotation (side)

9.3 External rotation (90 degrees)

9.4 Internal rotation $(90$ degrees)

10 Treatment complications

10.1 Arthroscopic repair

10.2 Arthroscopic lavage

11 Patient dissatisfaction

11.1 Arthroscopic repair

11.2 Arthroscopic lavage
Risk Ratio (M-H, Fixed, 95\% CI)

Risk Ratio (M-H, Fixed, 95\% CI)

Risk Ratio (M-H, Fixed, 95\% CI)

Risk Ratio (M-H, Fixed, 95\% CI)

Mean Difference (IV, Fixed, 95\% CI)

Mean Difference (IV, Fixed, 95\% CI)

Mean Difference (IV, Fixed, 95\% CI)

Mean Difference (IV, Fixed, 95\% CI)

Mean Difference (IV, Fixed, 95\% CI)

122

62

60

Risk Ratio (M-H, Fixed, 95\% CI)

Risk Ratio (M-H, Fixed, 95\% CI)

Risk Ratio (M-H, Fixed, 95\% CI)

Risk Ratio (M-H, Fixed, 95\% CI)

60

Risk Ratio (M-H, Fixed, 95\% CI)

Risk Ratio (M-H, Fixed, 95\% CI)

Totals not selected

Totals not selected

Not estimable

Not estimable

Totals not selected

Not estimable

Not estimable

Not estimable

Not estimable

$3.0[0.13,69.31]$

$3.0[0.13,69.31]$

Not estimable

Subtotals only 0.21 [0.07, 0.64]

Not estimable

\section{Analysis I.I. Comparison I Surgical versus non-surgical treatment, Outcome I Non return to pre-injury level of activity.}

Review: Surgical versus non-surgical treatment for acute anterior shoulder dislocation

Comparison: I Surgical versus non-surgical treatment

Outcome: I Non return to pre-injury level of activity

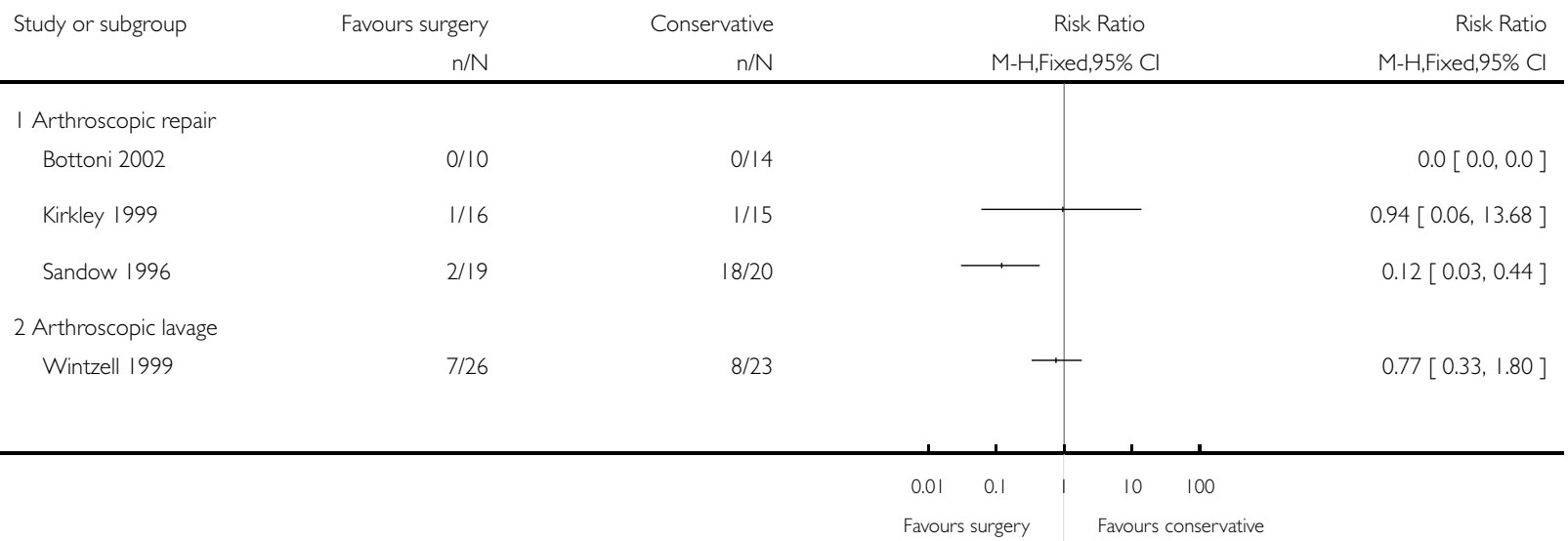


Analysis I.2. Comparison I Surgical versus non-surgical treatment, Outcome 2 Instability: redislocation or subluxation.

Review: Surgical versus non-surgical treatment for acute anterior shoulder dislocation

Comparison: I Surgical versus non-surgical treatment

Outcome: 2 Instability: redislocation or subluxation

\begin{tabular}{|c|c|c|c|c|c|}
\hline \multirow[t]{2}{*}{ Study or subgroup } & Surgery & Conservative & Risk Ratio & Weight & Risk Ratio \\
\hline & $n / N$ & $n / N$ & \multicolumn{2}{|l|}{ M-H,Fixed,95\% Cl } & M-H,Fixed,95\% Cl \\
\hline \multicolumn{6}{|l|}{ I Arthroscopic repair } \\
\hline Bottoni 2002 & $1 / 9$ & $9 / 12$ & $\longrightarrow$ & $16.0 \%$ & $0.15[0.02,0.97]$ \\
\hline Kirkley 1999 & $5 / 19$ & $11 / 19$ & $\mp$ & $22.8 \%$ & $0.45[0.20,1.06]$ \\
\hline Sandow 1996 & $2 / 19$ & $17 / 20$ & $\rightarrow$ & $34.3 \%$ & $0.12[0.03,0.47]$ \\
\hline Subtotal (95\% CI) & 47 & 51 & $<$ & $73.1 \%$ & $0.23[0.12,0.45]$ \\
\hline \multicolumn{6}{|c|}{ Total events: 8 (Surgery), 37 (Conservative) } \\
\hline \multicolumn{6}{|c|}{ Heterogeneity: $\mathrm{Chi}^{2}=3.52, \mathrm{df}=2(P=0.17) ; 1^{2}=43 \%$} \\
\hline \multicolumn{6}{|c|}{ Test for overall effect: $Z=4.27(P=0.000020)$} \\
\hline \multicolumn{6}{|l|}{2 Arthroscopic lavage } \\
\hline Wintzell 1999 & $4 / 30$ & $13 / 30$ & $\rightarrow$ & $26.9 \%$ & $0.31[0.11,0.84]$ \\
\hline Subtotal (95\% CI) & 30 & 30 & $\prec$ & $26.9 \%$ & $0.31[0.11,0.84]$ \\
\hline \multicolumn{6}{|c|}{ Total events: 4 (Surgery), 13 (Conservative) } \\
\hline \multicolumn{6}{|c|}{ Heterogeneity: not applicable } \\
\hline \multicolumn{6}{|c|}{ Test for overall effect: $Z=2.31(P=0.021)$} \\
\hline Total $(95 \% \mathrm{CI})$ & 77 & 81 & $\bullet$ & $100.0 \%$ & $0.25[0.14,0.44]$ \\
\hline \multicolumn{6}{|c|}{ Total events: 12 (Surgery), 50 (Conservative) } \\
\hline \multicolumn{6}{|c|}{ Heterogeneity: $\mathrm{Chi}^{2}=3.43, \mathrm{df}=3(P=0.33) ;\left.\right|^{2}=13 \%$} \\
\hline \multicolumn{6}{|c|}{ Test for overall effect: $Z=4.85(P<0.0000 \mathrm{I})$} \\
\hline
\end{tabular}


Analysis I.3. Comparison I Surgical versus non-surgical treatment, Outcome 3 Instability: redislocation or subluxation (minus I trial).

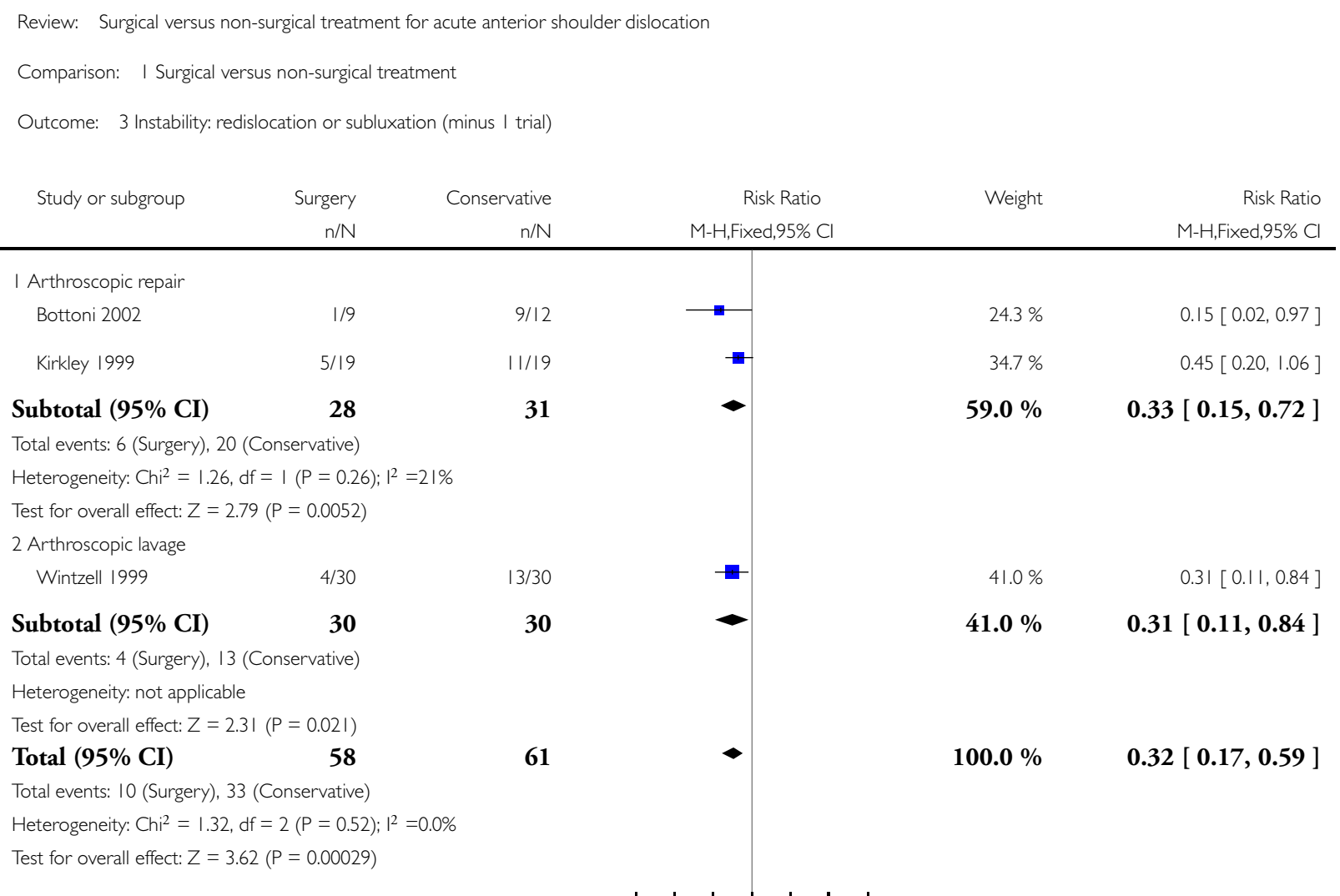


Analysis I.4. Comparison I Surgical versus non-surgical treatment, Outcome 4 Subsequent surgery for instability.

Review: Surgical versus non-surgical treatment for acute anterior shoulder dislocation

Comparison: I Surgical versus non-surgical treatment

Outcome: 4 Subsequent surgery for instability

\begin{tabular}{|c|c|c|c|c|c|}
\hline \multirow[t]{2}{*}{ Study or subgroup } & Surgery & Conservative & Risk Ratio & \multirow[t]{2}{*}{ Weight } & \multirow{2}{*}{$\begin{array}{r}\text { Risk Ratio } \\
\mathrm{M}-\mathrm{H}, \text { Fixed,95\% Cl}\end{array}$} \\
\hline & $\mathrm{n} / \mathrm{N}$ & $\mathrm{n} / \mathrm{N}$ & M-H,Fixed,95\% Cl & & \\
\hline \multicolumn{6}{|l|}{ I Arthroscopic repair } \\
\hline Bottoni 2002 & 1/9 & $6 / 12$ & $=$ & $30.9 \%$ & $0.22[0.03,1.53]$ \\
\hline Kirkley 1999 & $2 / 19$ & $7 / 19$ & $\rightarrow$ & $42.1 \%$ & $0.29[0.07,1.20]$ \\
\hline Subtotal (95\% CI) & 28 & 31 & $\longrightarrow$ & $73.0 \%$ & $0.26[0.08,0.82]$ \\
\hline \multicolumn{6}{|c|}{ Total events: 3 (Surgery), 13 (Conservative) } \\
\hline \multicolumn{6}{|c|}{ Heterogeneity: $\mathrm{Chi}^{2}=0.04, \mathrm{df}=\mathrm{I}(\mathrm{P}=0.84) ; \mathrm{I}^{2}=0.0 \%$} \\
\hline \multicolumn{6}{|c|}{ Test for overall effect: $Z=2.29(P=0.022)$} \\
\hline \multicolumn{6}{|l|}{2 Arthroscopic lavage } \\
\hline Wintzell 1999 & $0 / 30$ & $4 / 30$ & + & $27.0 \%$ & $0.11[0.01,1.98]$ \\
\hline Subtotal (95\% CI) & 30 & 30 & & $27.0 \%$ & $0.11[0.01,1.98]$ \\
\hline \multicolumn{6}{|c|}{ Total events: 0 (Surgery), 4 (Conservative) } \\
\hline \multicolumn{6}{|c|}{ Heterogeneity: not applicable } \\
\hline \multicolumn{6}{|c|}{ Test for overall effect: $Z=1.50(P=0.13)$} \\
\hline Total $(95 \% \mathrm{CI})$ & 58 & 61 & - & $100.0 \%$ & $0.22[0.08,0.64]$ \\
\hline \multicolumn{6}{|c|}{ Total events: 3 (Surgery), 17 (Conservative) } \\
\hline \multicolumn{6}{|c|}{ Heterogeneity: $\mathrm{Ch}^{2}=0.35, \mathrm{df}=2(P=0.84) ; \mathrm{I}^{2}=0.0 \%$} \\
\hline Test for overall effect: $Z=$ & $=0.0054)$ & & & & \\
\hline
\end{tabular}

$0.0010 .010 .1 \quad 1 \quad 10 \quad 1001000$

Favours surgery Favours conservative 
Analysis I.5. Comparison I Surgical versus non-surgical treatment, Outcome 5 WOSI (Western Ontario Shoulder Instability Index) scores at 32 months.

\footnotetext{
Review: Surgical versus non-surgical treatment for acute anterior shoulder dislocation

Comparison: I Surgical versus non-surgical treatment

Outcome: 5 WOSI (Western Ontario Shoulder Instability Index) scores at 32 months
}

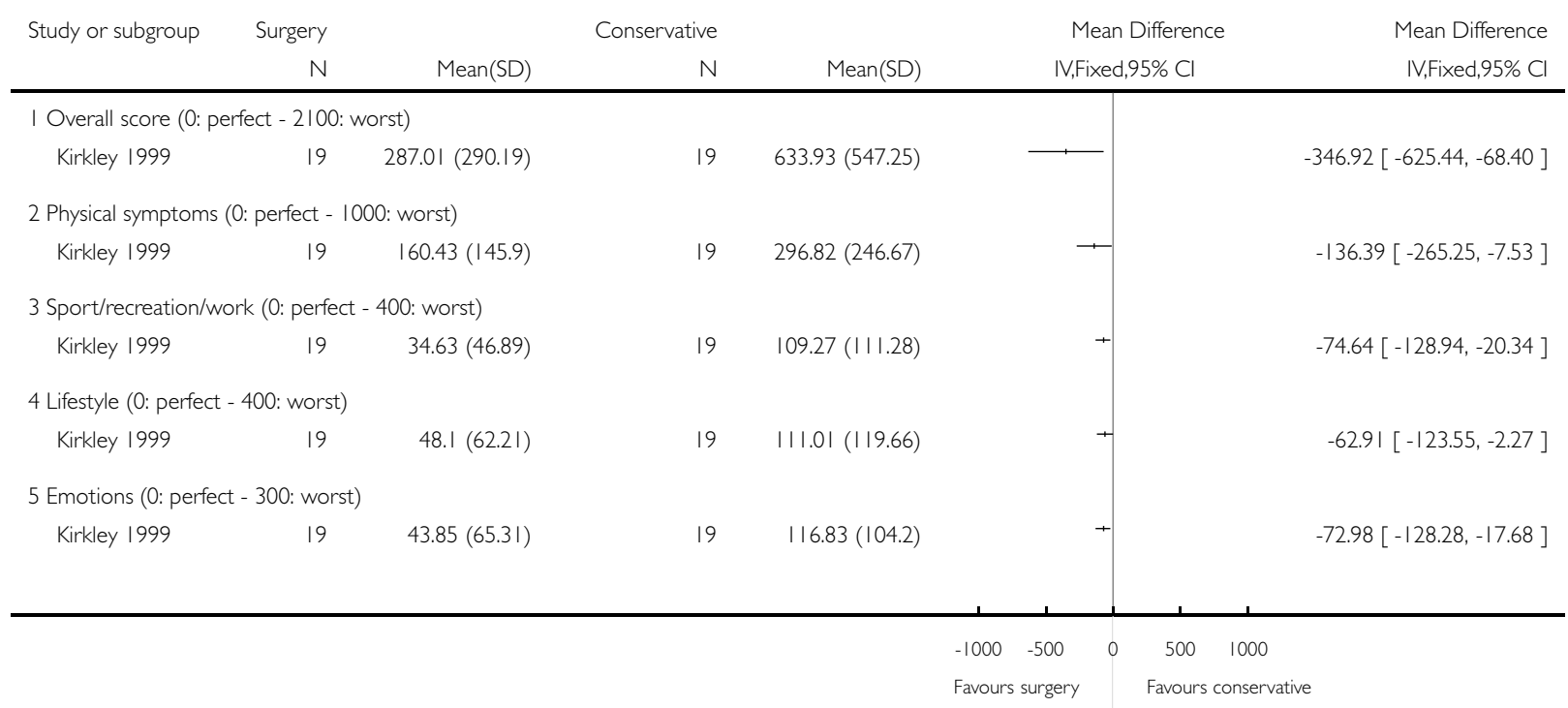


Analysis I.6. Comparison I Surgical versus non-surgical treatment, Outcome 6 WOSI (Western Ontario Shoulder Instability Index) scores at 79 months.

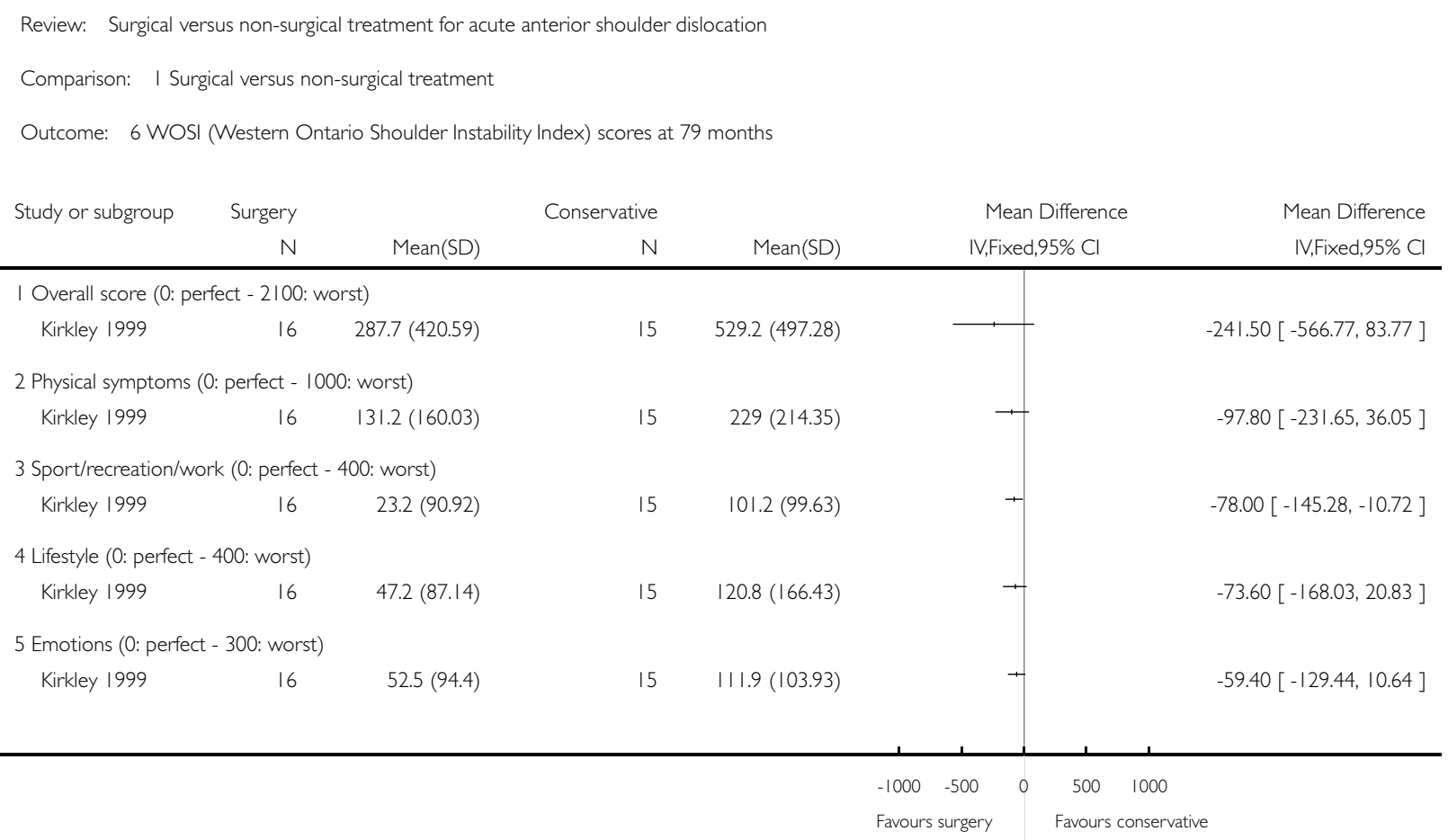

Analysis I.7. Comparison I Surgical versus non-surgical treatment, Outcome 7 Rowe shoulder score: fair or poor score.

Review: Surgical versus non-surgical treatment for acute anterior shoulder dislocation

Comparison: I Surgical versus non-surgical treatment

Outcome: 7 Rowe shoulder score: fair or poor score

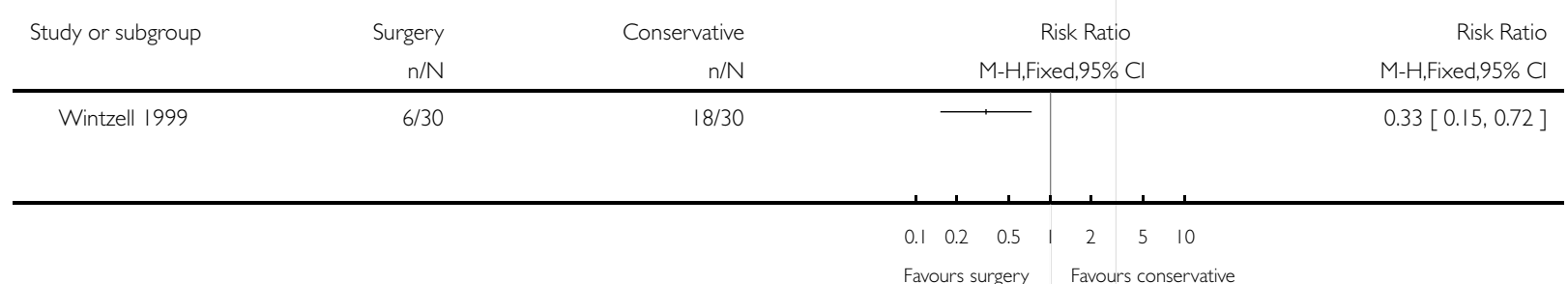


Analysis I.8. Comparison I Surgical versus non-surgical treatment, Outcome 8 Objective instability: positive apprehension test.

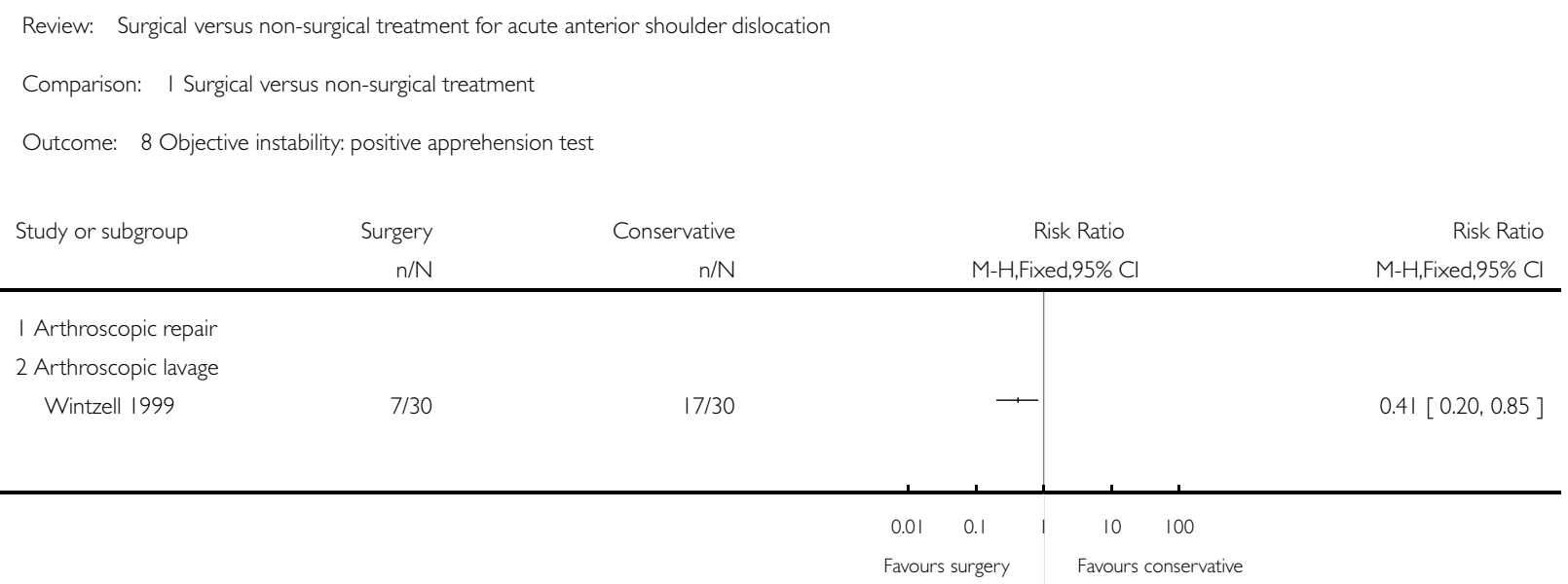

Analysis I.9. Comparison I Surgical versus non-surgical treatment, Outcome 9 Range of movement: \% of normal side.

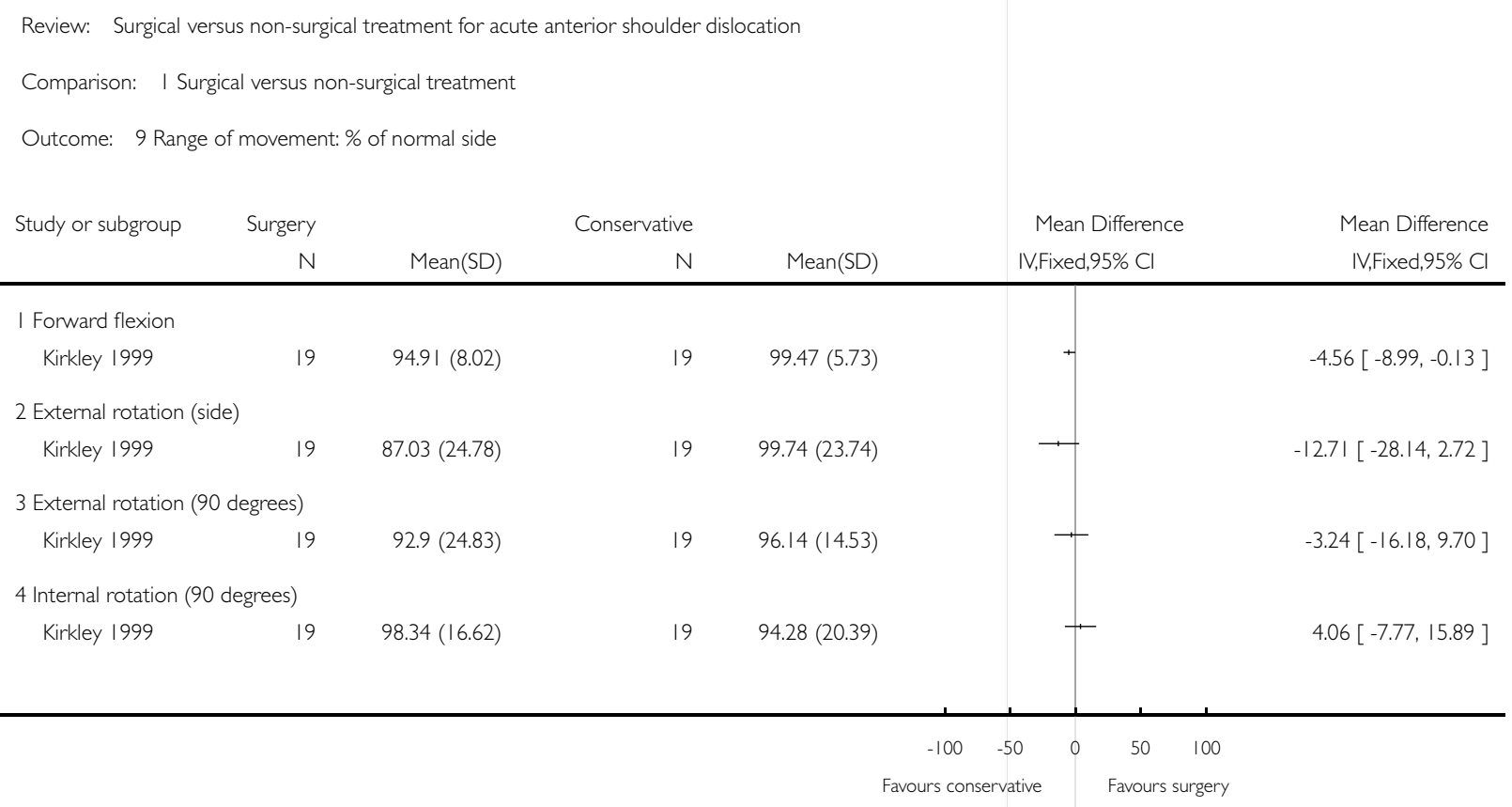




\section{Analysis I.10. Comparison I Surgical versus non-surgical treatment, Outcome 10 Treatment complications.}

Review: Surgical versus non-surgical treatment for acute anterior shoulder dislocation

Comparison: I Surgical versus non-surgical treatment

Outcome: 10 Treatment complications

$\begin{array}{llll}\text { Study or subgroup } & \text { Surgery } & \text { Conservative } & \text { Risk Ratio Ratio }\end{array}$

$\mathrm{n} / \mathrm{N} \quad \mathrm{n} / \mathrm{N}$

$\mathrm{n} / \mathrm{N} \quad \mathrm{M}-\mathrm{H}$, Fixed, $95 \% \mathrm{C}$

M-H,Fixed,95\% Cl

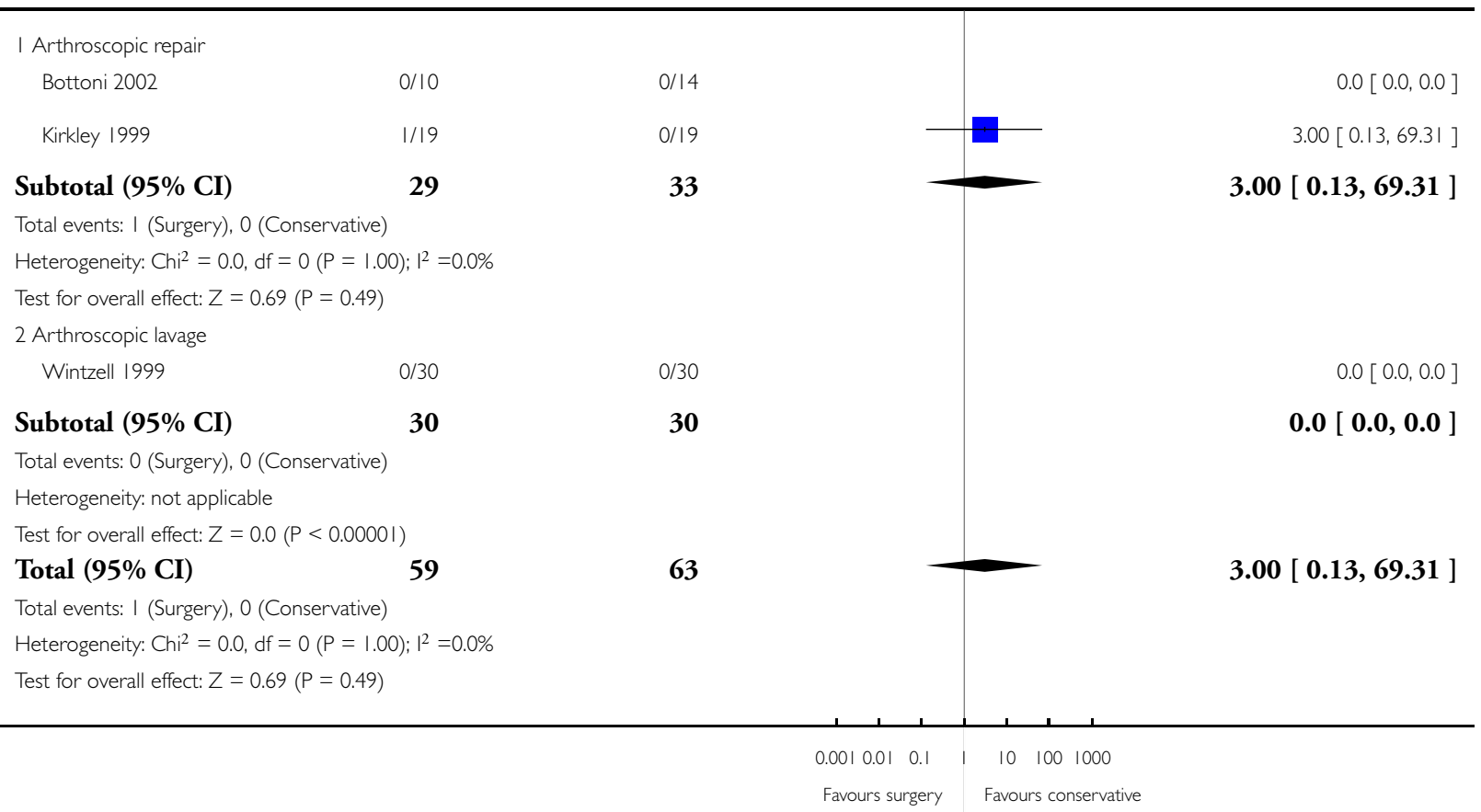


Analysis I.I I. Comparison I Surgical versus non-surgical treatment, Outcome II Patient dissatisfaction.

Review: Surgical versus non-surgical treatment for acute anterior shoulder dislocation

Comparison: I Surgical versus non-surgical treatment

Outcome: II Patient dissatisfaction

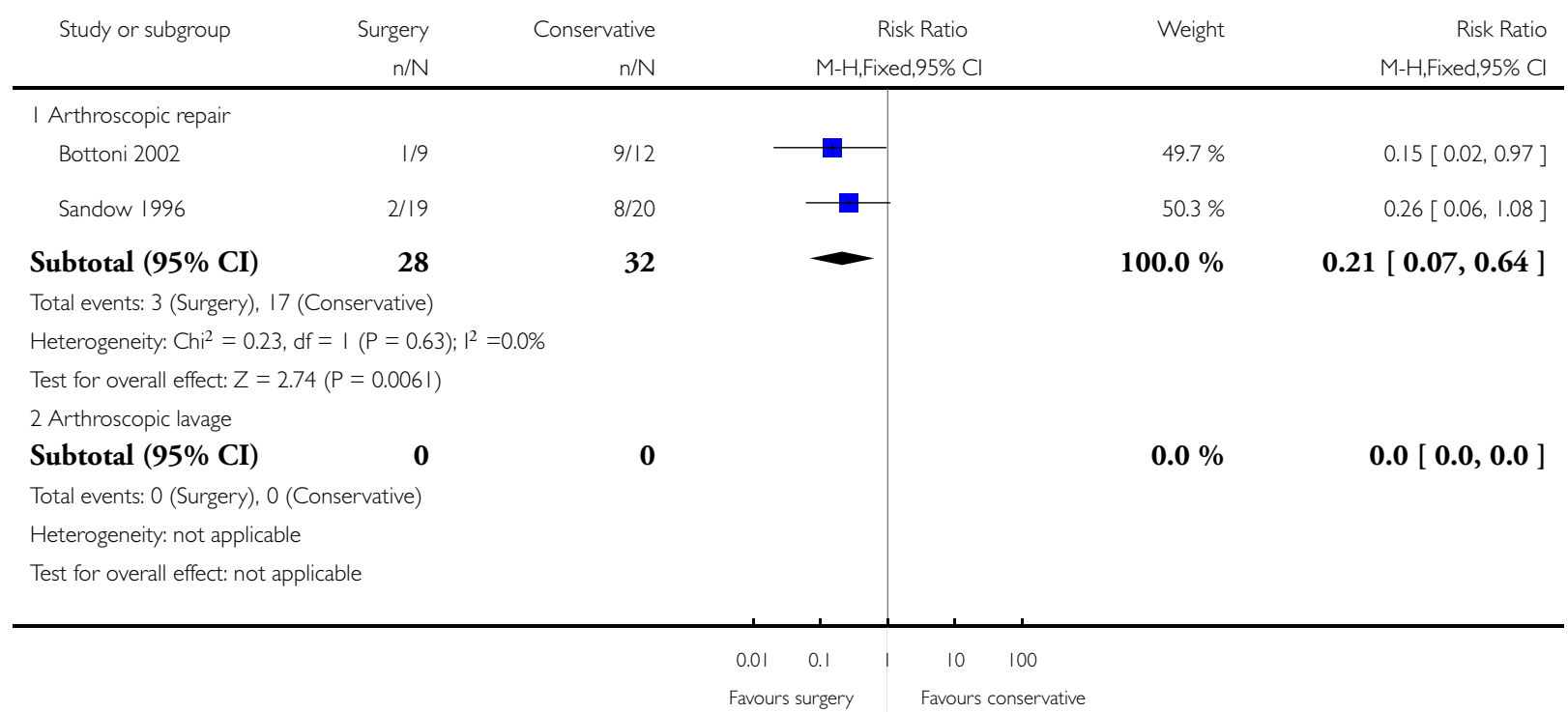

A P PENDICES

\section{Appendix I. Search strategies}

The Cochrane Library (Wiley InterScience interface)

\#1 MeSH descriptor Shoulder Dislocation, this term only

\#2 ((shoulder* near dislocat*) or (shoulder* near sublux*) or (shoulder* near instability) or (shoulder* near unstable)):ti,ab,kw \#3 ((glenohumeral next joint) or (glenohumeral next instability) or (glenohumeral next unstable)):ti,ab,kw

\#4 (lesion* near/3 hill next sachs) or (lesion* near/3 bankart):ti,ab,kw

\#5 (\#1 OR \#2 OR \#3 OR \#4)

\#6 ((Bankart) or (Putti-Platt)):ti,ab

\#7 (arthroscop* or repai* $^{*}$ or operation or surgery or stabilis* or stabiliz*):ti,ab

\#8 (\#6 OR \#7)

\#9 (\#5 AND \#8) (78 records: 2009, issue 3)

\section{MEDLINE (Ovid interface)}

1. Shoulder Dislocation/

2. (shoulder $\$$ adj3 (dislocat $\$$ or sublux $\$$ or instability or unstable)).tw.

3. (glenohumeral adj (joint or instability or unstable)).tw.

4. hill sachs lesion.tw.

Surgical versus non-surgical treatment for acute anterior shoulder dislocation (Review)

Copyright (C) 2010 The Cochrane Collaboration. Published by John Wiley \& Sons, Ltd. 
5. or/ $1-4$

6. Bankart.tw.

7. Putti-Platt.tw.

8. (arthroscop\$ or repair\$ or operation or surgery or stabilis\$ or stabiliz $\$$ ).tw.

9. su.fs.

10. or/6-9

11. and $/ 5,10$

12. randomized controlled trial.pt.

13. controlled clinical trial.pt.

14. Randomized Controlled Trials/

15. Random Allocation/

16. Double Blind Method/

17. Single Blind Method/

18. or/12-17

19. Animals/ not Humans/

20. 18 not 19

21. clinical trial.pt.

22. exp Clinical Trials/

23. (clinic $\$$ adj25 trial\$).tw.

24. ((singl\$ or doubl\$ or trebl\$ or tripl\$) adj25 (blind\$ or mask\$)).tw.

25. Placebos/

26. placebo\$.tw.

27. random $\$ . t w$.

28. Research Design/

29. or/21-28

30. 29 not 19

31. 30 not 20

32. Comparative Study.pt.

33. exp Evaluation Studies/

34. Follow Up Studies/

35. Prospective Studies/

36. (control\$ or prospectiv\$ or volunteer $\$$ ).tw.

37. or/32-36

38. 37 not 19

39. 38 not $(20$ or 31$)$

40. or $/ 20,31,39$

41. and/11,40 (327 records: August week 1 2009)

\section{EMBASE (Ovid interface)}

1. Shoulder Dislocation/

2. (shoulder $\$$ adj3 (dislocat $\$$ or sublux $\$$ or instability or unstable)).tw.

3. (glenohumeral adj (joint or instability or unstable)).tw.

4. hill sachs lesion.tw.

5. or/1-4

6. Bankart.tw.

7. Putti-Platt.tw.

8. (arthroscop\$ or repair\$ or operation or surgery or stabilis\$ or stabiliz\$).tw.

9. su.fs.

10. or/6-9

11. and $/ 5,10$

12. exp Randomized Controlled trial/

13. exp Double Blind Procedure/

Surgical versus non-surgical treatment for acute anterior shoulder dislocation (Review)

Copyright $\odot 2010$ The Cochrane Collaboration. Published by John Wiley \& Sons, Ltd. 
14. exp Single Blind Procedure/

15. exp Crossover Procedure/

16. Controlled Study/

17. or/12-16

18. ((clinical or controlled or comparative or placebo or prospective\$ or randomi\#ed) adj3 (trial or study)).tw.

19. (random $\$ \operatorname{adj} 7$ (allocat $\$$ or allot $\$$ or assign $\$$ or basis $\$$ or $\operatorname{divid} \$$ or order $\$$ )).tw.

20. ((singl\$ or doubl\$ or trebl\$ or tripl\$) adj7 (blind $\$$ or mask\$)).tw.

21. (cross?over\$ or (cross adj1 over\$)).tw.

22. ( (allocat $\$$ or allot $\$$ or assign $\$$ or divid $\$$ ) adj3 (condition $\$$ or experiment $\$$ or intervention $\$$ or treatment $\$$ or therap $\$$ or control $\$$ or group\$)).tw.

23. or/ $18-22$

24. or/ 17,23

25. limit 24 to human

26. and/11,25 (252 records: 2009 week 32)

\section{WHAT'S NEW}

Last assessed as up-to-date: 13 August 2009.

\begin{tabular}{l|l|l}
30 October 2009 & New search has been performed & $\begin{array}{l}\text { In this third update of our review (Issue 1, 2010), the literature search was } \\
\text { updated to } 14 \text { August 2009. We located another conference abstract of an } \\
\text { already included trial, and a full report of (and commentary on) an already ex- } \\
\text { cluded trial. Other changes reflected revised style, format and methodological } \\
\text { guidelines of The Cochrane Collaboration. There was no important change } \\
\text { made to the conclusions. }\end{array}$ \\
\hline
\end{tabular}

\section{H I S T O R Y}

Protocol first published: Issue 3, 2003

Review first published: Issue 1, 2004

\begin{tabular}{|c|c|c|}
\hline 9 May 2008 & Amended & Converted to new review format. \\
\hline 15 June 2007 & New search has been performed & $\begin{array}{l}\text { In our second update of our review (Issue } 1,2008 \text { ), the literature search was } \\
\text { extended to June } 2007 \text {. We located a full publication of an already included } \\
\text { trial. Based on the new information on the interventions, this trial was excluded. } \\
\text { Other changes reflected revised style, format and methodological guidelines of } \\
\text { The Cochrane Collaboration. There was no important change made to the con- } \\
\text { clusions. }\end{array}$ \\
\hline
\end{tabular}

12 May 2005 New search has been performed

In the first update (designated minor: Issue 3, 2005) of our review we extended the literature search to January 2005. We located one new study, subsequently excluded, and a full publication of the longer-term follow-up results for Kirkley 1999 (an already included trial). We also received and added to the review further 

next update) and Kirkley 1999. There was no important change made to the conclusions.

\section{CONTRIBUTIONS OFAUTHORS}

Mohammed Al-Maiyah (MA) initiated the review, prepared the first drafts of the protocol and main text of the review, and provided the main clinical input. Helen Handoll $(\mathrm{HH})$, who provided methodological support throughout, critically rewrote all drafts, and designed and compiled the analyses and other tables and completed the review. Both MA and HH searched for studies, performed independent study selection and assessment, and sought additional information from trialists. Amar Rangan undertook study selection and critically reviewed various drafts of the first version.

The first, second and third updates were prepared by $\mathrm{HH}$ and checked over by MA.

Mohammed Al-Maiyah and Helen Handoll are the guarantors for the review.

\section{DECLARATIONS OF INTEREST}

None known.

\section{SOURCES OFSUPPORT}

\section{Internal sources}

- University of Teesside, UK.

\section{External sources}

- No sources of support supplied

\section{NDEX TERMS}

\section{Medical Subject Headings (MeSH)}

Randomized Controlled Trials as Topic; Shoulder Dislocation [surgery; *therapy] 


\section{MeSH check words}

Adult; Humans; Male 